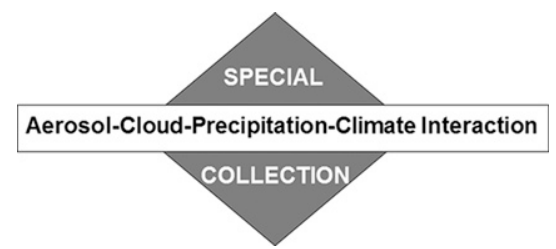

\title{
¿Impacts of Varying Concentrations of Cloud Condensation Nuclei on Deep Convective Cloud Updrafts-A Multimodel Assessment
}

\author{
Peter J. Marinescu, ${ }^{a}$ Susan C. van den Heever, ${ }^{a}$ Max Heikenfeld, ${ }^{\mathrm{b}}$ Andrew I. Barrett,${ }^{\mathrm{c}}$ \\ Christian Barthlott, ${ }^{\mathrm{c}}$ Corinna Hoose, ${ }^{\mathrm{c}}$ Jiwen FAn, ${ }^{\mathrm{d}}$ ANn M. Fridlind, ${ }^{\mathrm{e}}$ Toshi Matsui,${ }^{\mathrm{f}, \mathrm{g}}$ \\ Annette K. Miltenberger, ${ }^{\text {h,i }}$ Philip Stier, ${ }^{\mathrm{b}}$ Benoit Vie, ${ }^{\mathrm{j}}$ Bethan A. White, ${ }^{\mathrm{b}, \mathrm{k}}$ And Yuwei Zhang ${ }^{\mathrm{d}}$ \\ ${ }^{a}$ Department of Atmospheric Science, Colorado State University, Fort Collins, Colorado \\ ${ }^{\mathrm{b}}$ Atmospheric, Oceanic and Planetary Physics, Department of Physics, University of Oxford, Oxford, United Kingdom \\ ${ }^{\mathrm{c}}$ Institute of Meteorology and Climate Research (IMK-TRO), Karlsruhe Institute of Technology, Karlsruhe, Germany \\ d Pacific Northwest National Laboratory, Richland, Washington \\ ${ }^{\mathrm{e}}$ NASA Goddard Institute for Space Studies, New York, New York \\ ${ }^{\mathrm{f}}$ NASA Goddard Space Flight Center, Greenbelt, Maryland \\ ${ }^{\mathrm{g}}$ Earth System Science Interdisciplinary Center, University of Maryland, College Park, College Park, Maryland \\ ${ }^{\mathrm{h}}$ School of Earth and Environment, University of Leeds, Leeds, United Kingdom \\ ${ }^{\mathrm{i}}$ Institute for Atmospheric Physics, Johannes Gutenberg University, Mainz, Germany \\ ${ }^{\mathrm{j}}$ Météo-France, Toulouse, France \\ ${ }^{\mathrm{k}}$ School of Earth, Atmosphere and Environment, Monash University, Melbourne, Victoria, Australia
}

(Manuscript received 8 July 2020, in final form 3 December 2020)

\begin{abstract}
This study presents results from a model intercomparison project, focusing on the range of responses in deep convective cloud updrafts to varying cloud condensation nuclei $(\mathrm{CCN})$ concentrations among seven state-of-the-art cloudresolving models. Simulations of scattered convective clouds near Houston, Texas, are conducted, after being initialized with both relatively low and high CCN concentrations. Deep convective updrafts are identified, and trends in the updraft intensity and frequency are assessed. The factors contributing to the vertical velocity tendencies are examined to identify the physical processes associated with the $\mathrm{CCN}$-induced updraft changes. The models show several consistent trends. In general, the changes between the High-CCN and Low-CCN simulations in updraft magnitudes throughout the depth of the troposphere are within $15 \%$ for all of the models. All models produce stronger $(\sim+5 \%-15 \%)$ mean updrafts from $\sim 4-7 \mathrm{~km}$ above ground level (AGL) in the High-CCN simulations, followed by a waning response up to $\sim 8 \mathrm{~km}$ AGL in most of the models. Thermal buoyancy was more sensitive than condensate loading to varying $\mathrm{CCN}$ concentrations in most of the models and more impactful in the mean updraft responses. However, there are also differences between the models. The change in the amount of deep convective updrafts varies significantly. Furthermore, approximately half the models demonstrate neutral-to-weaker ( $\sim-5 \%$ to $0 \%)$ updrafts above $\sim 8 \mathrm{~km}$ AGL, while the other models show stronger $(\sim+10 \%)$ updrafts in the High-CCN simulations. The combination of the $\mathrm{CCN}$-induced impacts on the buoyancy and vertical perturbation pressure gradient terms better explains these middle- and upper-tropospheric updraft trends than the buoyancy terms alone.
\end{abstract}

KEYWORDS: Aerosol-cloud interaction; Aerosol indirect effect; Cloud microphysics; Convective-scale processes; Cloud resolving models; Model comparison; Updrafts/downdrafts

\section{Introduction}

One of the primary and most studied pathways in which aerosol particles interact with deep convective clouds is via their ingestion into convective updrafts. Within these updrafts, supersaturated conditions develop, and aerosol particles can serve as cloud condensation nuclei $(\mathrm{CCN})$, forming

\footnotetext{
D Denotes content that is immediately available upon publication as open access.
}

Corresponding author: Peter James Marinescu, peter.marinescu@ colostate.edu cloud droplets (Köhler 1936). By altering the number concentrations of CCN that enter a cloud's updraft, the number concentrations and sizes of the cloud droplets within the updraft can also vary, particularly in $\mathrm{CCN}$-limited regimes (e.g., Reutter et al. 2009), which then may have many subsequent feedbacks on a cloud's characteristics and evolution (e.g., Twomey 1977; Albrecht 1989). Typically, the majority of $\mathrm{CCN}$ are ingested through the bases of deep convective clouds within the atmospheric boundary layer, although several studies have shown that some fraction of CCN in the middle troposphere can also become entrained within deep convective updrafts, form cloud droplets, and subsequently impact the cloud development (Fridlind et al. 2004; Lebo 2014; Marinescu et al. 2017). 
When the number concentrations of $\mathrm{CCN}$ that are ingested into an updraft are increased, the initial response is an increase in the cloud droplet number concentration which, for the same liquid water contents results in smaller cloud droplet sizes due to increased competition for the available water vapor (e.g., Twomey and Squires 1959). While this first step in the chain of aerosol-updraft interactions is well understood, many studies have shown that the subsequent responses in deep convective cloud updrafts are complex and have had conflicting results (e.g., Khain et al. 2005; van den Heever et al. 2006; Tao et al. 2007; Fan et al. 2009; Barthlott and Hoose 2018).

One of the most prevailing theories on these subsequent processes within deep convective updrafts is the concept of $\mathrm{CCN}$-induced convective invigoration, originally reported in both observational and modeling studies (e.g., Andreae et al. 2004; Khain et al. 2005; Wang 2005; van den Heever et al. 2006; Lin et al. 2006). Generally, CCN-induced convective invigoration refers to the increase in the vertical velocity magnitude within convective cloud updrafts when exposed to higher concentrations of $\mathrm{CCN}$. Due to higher number concentrations of cloud droplets that form, more latent heating occurs, resulting in more buoyant (i.e., invigorated) updrafts. However, the specific process that causes the enhancements in buoyancy has been shown to vary. For example, some studies have reported that the increased latent heating within deep convective updrafts under relatively high $\mathrm{CCN}$ concentrations is primarily the result of increased condensation due to the higher number concentrations of cloud droplets (e.g., Wang 2005; Fan et al. 2007, 2018; Seiki and Nakajima 2014; Sheffield et al. 2015; Lebo 2018). Other studies have shown, however, that when a deep convective cloud is exposed to higher concentrations of $\mathrm{CCN}$, more of the cloud's liquid water reaches the mixed-phase region and freezes, and the additional latent heating induced by enhanced freezing processes is a major factor driving the intensified updrafts (e.g., Khain et al. 2005; Seifert and Beheng 2006b; van den Heever et al. 2006; Rosenfeld et al. 2008). Furthermore, a number of studies have shown that when exposed to higher concentrations of CCN, some deep convective updrafts remain unchanged or weaken (e.g., Tao et al. 2007; Fan et al. 2009; Lebo and Seinfeld 2011; Barthlott and Hoose 2018), contradictory to the invigoration concepts described above. Even for one of the most established concepts on the interactions of aerosol particles with deep convective clouds, the results appear to be muddled due to the complex kinematic and microphysics processes and feedbacks in deep convection.

These seemingly conflicting results have been attributed to the many differences between the various studies. For example, the type of deep convective cloud system under consideration can alter the effect that aerosol particles have within deep convective updrafts (e.g., Seifert and Beheng 2006b; Khain et al. 2008; van den Heever et al. 2011). Supercells that are primarily driven by dynamical forcings have been shown to have lesser impacts from varying CCN concentrations than other types of deep convection (e.g., Grant and van den Heever 2015). Another cause of complication stems from differences in studies that focus on one cloud or cloud system versus others that consider larger domains with a field of clouds. Furthermore, even for the same type of convection, the updraft magnitude response to increased $\mathrm{CCN}$ concentrations have been shown to be sensitive to the environmental conditions in which the clouds form. Idealized simulations, in which these environmental parameters can be systematically varied and assessed, have also demonstrated that the response in deep convective updraft magnitude to increased $\mathrm{CCN}$ concentrations is sensitive to boundary layer moisture (e.g., Fan et al. 2007), convective available potential energy (CAPE; Lee et al. 2008; Storer et al. 2010), and wind shear (Lee et al. 2008; Fan et al. 2009). Case study simulations, which often provide more realism than idealized simulations, have also been used to assess the impacts of environmental parameters. For example, mesoscale convective systems in environments with different relative humidity (Khain et al. 2005; Fan et al. 2007; Tao et al. 2007, Iguchi et al. 2020) and shear conditions (Khain et al. 2008; Marinescu et al. 2017; Chen et al. 2020) have shown different responses of the updraft magnitude for similar perturbations in $\mathrm{CCN}$ concentrations.

In addition to different deep convective cloud types and atmospheric conditions, modeling studies on the effects of $\mathrm{CCN}$ on deep convective clouds have also used a diverse set of models with varying physical parameterizations and dynamical cores. As compared to those studies that have explored aerosol-cloud interactions with just one model, relatively few studies have explored the impacts of $\mathrm{CCN}$ in deep convective updrafts using a range of different models. These few studies have typically utilized the same dynamical model and substituted different microphysical parameterizations to assess the dependency of the $\mathrm{CCN}$-induced deep convective updraft response to the microphysical parameterization. Some of these studies use the same kinematic fields for each simulation in order to better isolate the specific microphysical processes that drive different results between the parameterizations [e.g., piggybacking approach in Grabowski (2015) and Grabowski and Morrison (2017) or kinematic driver approach in Hill et al. (2015)] but consequentially cannot examine $\mathrm{CCN}$-induced impacts on the cloud microphysical-dynamical feedback processes. Other studies perform multiple simulations with the same numerical model, changing only the microphysical parameterization at each simulation's initialization and allowing each simulation to evolve individually (e.g., Seifert et al. 2006; Khain et al. 2009; White et al. 2017). These latter studies primarily compared aerosol effects on deep convection with bulk and bin microphysical schemes (e.g., Seifert et al. 2006; Khain et al. 2009; Khain and Lynn 2009; Lebo et al. 2012; Fan et al. 2012), which fundamentally differ in how they represent hydrometeor size distributions. [For a comprehensive comparison of bulk and bin microphysical parameterizations, see Khain et al. (2015).] These studies found both consistencies (Seifert et al. 2006; Khain et al. 2009) and inconsistencies (Khain and Lynn 2009; Lebo and Seinfeld 2011; Lebo et al. 2012; Fan et al. 2012; White et al. 2017) in the deep convective updraft response to increased CCN concentrations, with some of these differences being attributed to the use of saturation adjustment (Khain and Lynn 2009; Lebo et al. 2012) and the representation of aerosol nucleation sinks (Fan et al. 2012).

These complex interactions between $\mathrm{CCN}$ concentrations and deep convection motivates the need for systematic multimodel comparisons to provide better insights into the range of aerosolimpacted deep convective cloud responses from different 

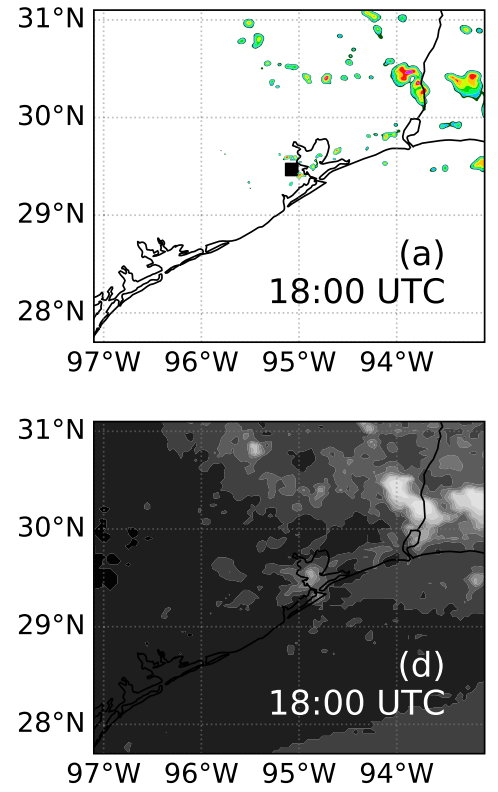
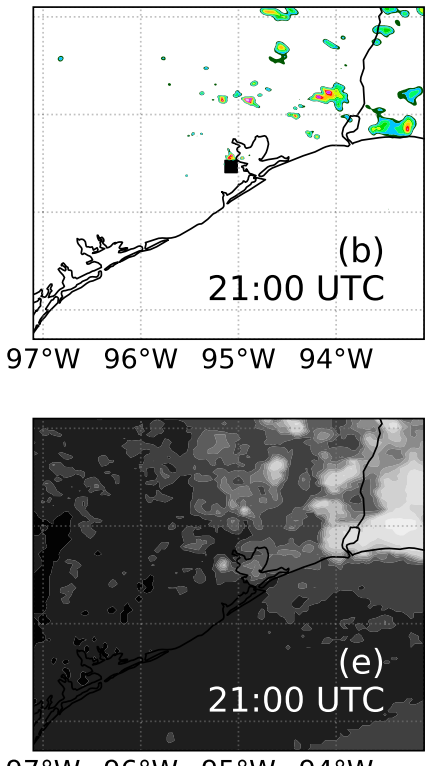

$97^{\circ} \mathrm{W} \quad 96^{\circ} \mathrm{W} \quad 95^{\circ} \mathrm{W} \quad 94^{\circ} \mathrm{W}$
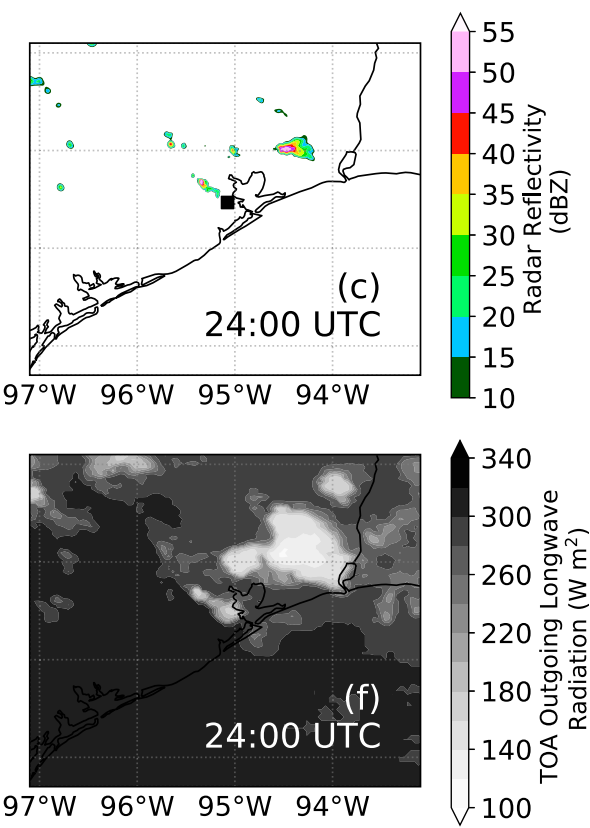

FIG. 1. Evolution of KHGX (Houston NEXRAD; black square) radar reflectivity at approximately (a) 1800, (b) 2100, (c) 2400 UTC, centered around Houston. Radar reflectivity is gridded and shown at $\sim 3.0 \mathrm{~km}$ AGL. (d)-(f) The evolution of outgoing longwave radiation from the NOAA GOES satellite at the same times as in (a)-(c).

models. Such an effort has now been completed through the multi-institutional collaborations of the Aerosol-CloudPrecipitation-Climate international working group (ACPC)-a cooperation of the International Geosphere-Biosphere Programme's Integrated Land Ecosystem-Atmosphere Processes Study and International Global Atmospheric Chemistry and the World Climate Research Programme's Global Energy and Water Cycle Experiment. ACPC was first developed in 2007 and focuses on understanding and reducing the uncertainties associated with aerosol-cloud interactions (Rosenfeld et al. 2014; www.acpcinitiative.org). Within ACPC, a model intercomparison project (MIP) was organized in order to assess the robustness of deep convective cloud responses to increased $\mathrm{CCN}$ concentrations in a wide range of models.

The research reported here is focused on the results obtained from the ACPC MIP, whereby seven different models from different institutions simulated the same case study of scattered deep convective clouds near Houston, Texas. Simulating the same case study forces all the models to produce similar types of clouds in comparable environments, while still allowing the models to freely evolve and produce their own realizations of the event, including the critical, realistic feedbacks between cloud dynamical and microphysical processes. These microphysicaldynamical feedbacks can dictate the net response of aerosols on deep convective cloud responses (e.g., van den Heever et al. 2006; Tao et al. 2007). The ACPC MIP represents the first time that a model intercomparison study has been used to study the effects of $\mathrm{CCN}$ on deep convective clouds. While complimentary studies are in preparation that will focus on assessing the ACPC MIP model responses in many of the simulated cloud characteristics (e.g., precipitation, anvils, and cold pools) and microphysical processes to varying $\mathrm{CCN}$ concentrations, the goals of the current study are 1) to quantify the range of responses in deep convective updraft velocities to increased $\mathrm{CCN}$ concentrations among a suite of state-of-the-art models and 2) to physically explain the updraft response variability among these models.

\section{2. АСРC MIP}

\section{a. Simulations}

The ACPC MIP simulations are based on a case of scattered convective clouds that developed near Houston on 19-20 June 2013. Figure 1 shows several radar and satellite snapshots during this event. In the late morning hours, there were weak, scattered, isolated convective clouds along a trailing front that extended zonally across the southeastern United States, into southern Louisiana and eastern Texas. With increased insolation in the late morning and early afternoon hours, the convection associated with this trailing front north and east of Houston became more intense (Figs. 1a,d). Together with the deepening boundary layer and a sea breeze, widespread scattered convective clouds were also generated along the coastal region. All the models captured these two regions of convective clouds and precipitation at the onset of this event (Figs. 2a-g), which can also be seen in the National Centers for Environmental Prediction's national stage IV quantitative precipitation estimate product (Du 2011; Fig. 2h). Isolated convective clouds continued to initiate, develop, and dissipate for several hours around the Houston area, with a few cells becoming intense, reaching the tropopause, and creating anvils (Fig. 1). The models also produced scattered convective clouds and precipitation throughout the entire convective event, with localized areas of more intense convection and precipitation both around and north and west of Houston (Figs. 2i-p). Nevertheless, there are 


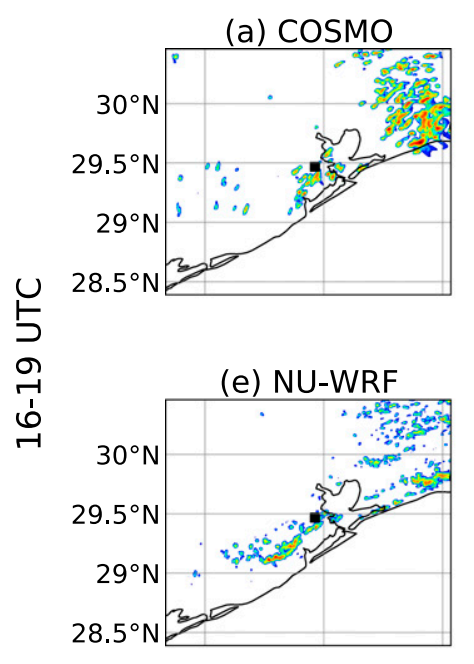

(b) MesoNH

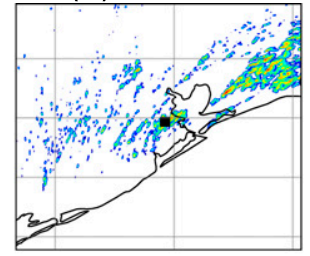

(f) WRF-Morr

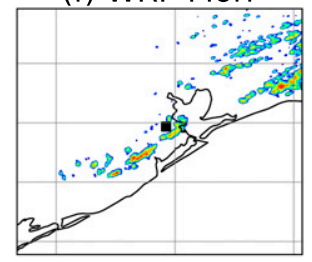

(j) MesoNH

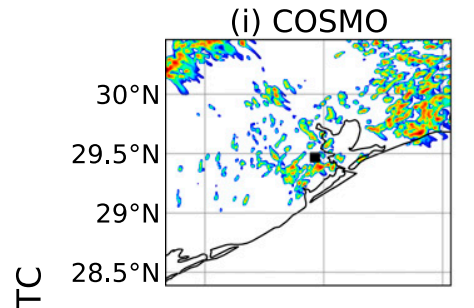

5
5
0
0
0

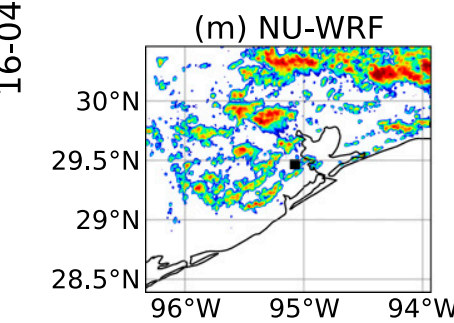

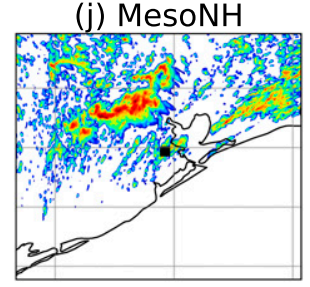

(n) WRF-Morr

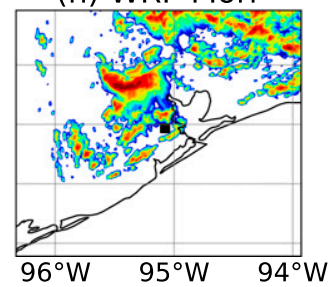

(c) RAMS

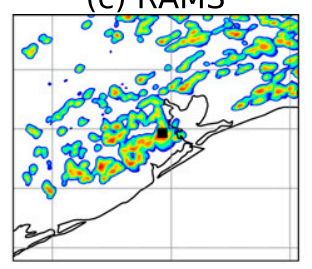

(g) WRF-SBM

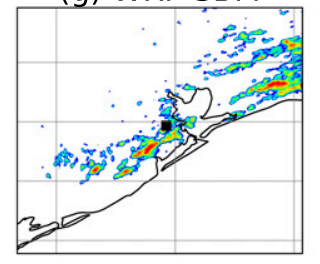

(k) RAMS

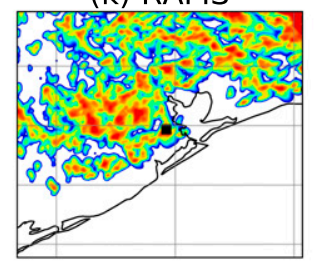

(o) WRF-SBM

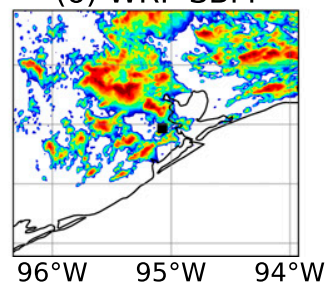

(d) UM

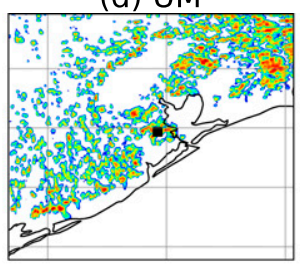

(h) Stage IV

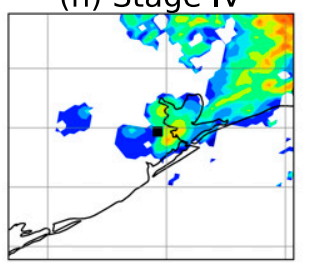

(I) UM

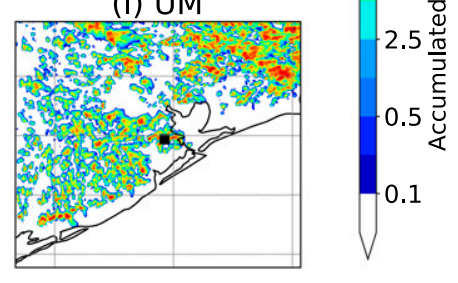

(p) Stage IV

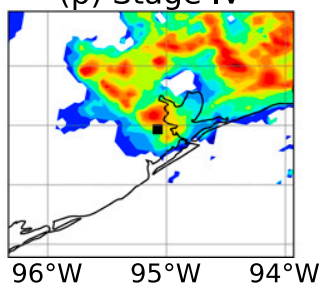

FIG. 2. Plan views of accumulated precipitation within the model's innermost domains and the stage IV product at two different times. Data are from the models' Low-CCN simulations (see section 2b), which had generally more precipitation than the High-CCN simulations. (a)-(h) Accumulated precipitation from 1600 to 1900 UTC 19 Jun 2013. (i)-(p) Accumulated precipitation from 1600 UTC 19 Jun to 0400 UTC 20 Jun 2013. The black square represents the location of the KHGX radar. Note that the model horizontal grid spacing is $0.5 \mathrm{~km}$, while the stage IV product grid spacing is $4.0 \mathrm{~km}$.

differences in the coverage and localized intensity of the precipitation between the models due to differences in their parameterizations, initialization, and subsequent evolution.

The models were able to reproduce the scattered nature of convection that was associated with this event by using atmospheric conditions representative of this case study. To facilitate model intercomparison, all modeling teams adhered, as closely as possible, to a set of previously tested simulation specifications (Table 1; van den Heever et al. 2018). Simulations utilized three one-way nested domains in order to capture the synoptic-scale influences (e.g., trailing front), while still resolving the deep convective clouds that formed. The focus of all of the analyses was on the innermost domain 3 (D3; Figs. 3a,b), which had $500 \mathrm{~m}$ horizontal grid spacing. The simulations were conducted for $27 \mathrm{~h}$ to capture the impacts of the $\mathrm{CCN}$ concentrations on the entire diurnal cycle. The model output was saved at a high frequency (every 5 min) during the 12-h period (1600-0400 UTC; 1100-2300 local time) when deep convective clouds were present in the observations and simulations within domain 3 . This 12 -h period will be the focus of the analyses in this study. To test the sensitivity to model output frequency, 1-min data from a shorter time period (2100-2400 UTC) was compared to the 5-min data from the same time period and produced similar results (not shown here). While all the participants in the ACPC MIP attempted to follow the specifications in Table 1 , some models were not equipped to adhere to all the specifications. These details of each model and the major differences between them are discussed in the next sections and are summarized in appendix A.

\section{b. Aerosol initialization}

For each participating model, two simulations were conducted with relatively high and low initial CCN concentrations (Fig. 3c). 
TABLE 1. ACPC MIP simulation specifications, as defined in the ACPC Deep Convective Cloud Road Map (van den Heever et al. 2018).

\begin{tabular}{|c|c|}
\hline Model configuration & Description \\
\hline Simulation period & 1200 UTC 19 Jun to 1500 UTC 20 Jun 2013 \\
\hline Total simulation hours & 27 \\
\hline Initialization and boundary data & $\begin{array}{l}\text { National Center of Environmental Prediction (NCEP) Global Data Assimilation } \\
\text { System (GDAS)/FNL (NCEP 2000) }\end{array}$ \\
\hline Number of model domains & 3 , one-way nesting only (no interactive nests) \\
\hline Horizontal grid spacing of each domain & $4.5 \mathrm{~km}, 1.5 \mathrm{~km}, 500 \mathrm{~m}$ \\
\hline $\begin{array}{l}\text { Number of horizontal grid points in each nest } \\
\text { (approximate size in } \mathrm{km} \text { of each domain) }\end{array}$ & $\begin{array}{l}4.5 \mathrm{~km} \text { domain: } 400 \times 400 \text { grid points }(\sim 1800 \mathrm{~km} \times 1800 \mathrm{~km}) \\
1.5 \mathrm{~km} \text { domain: } 547 \times 547 \text { grid points }(\sim 820 \mathrm{~km} \times 820 \mathrm{~km}) \\
500 \mathrm{~m} \text { domain: } 500 \times 500 \text { grid points }(\sim 250 \mathrm{~km} \times 250 \mathrm{~km})\end{array}$ \\
\hline Vertical levels & 95 , stretched from approximately $50 \mathrm{~m}$ near the surface to $300 \mathrm{~m}$ around $4 \mathrm{~km} \mathrm{AGL}$ \\
\hline Model top & Approximately $22 \mathrm{~km} / 50 \mathrm{hPa}$ \\
\hline Center latitude and longitude & $29.4719^{\circ} \mathrm{N}, 95.0792^{\circ} \mathrm{W}$ (same for all domains) \\
\hline Model time steps & $\begin{array}{l}4.5 \mathrm{~km} \text { domain: } 6 \mathrm{~s} \\
1.5 \mathrm{~km} \text { domain: } 3 \mathrm{~s} \\
500 \mathrm{~m} \text { domain: } 3 \mathrm{~s}\end{array}$ \\
\hline Convection parameterization & No convection or cumulus scheme in any of the three domains \\
\hline
\end{tabular}

These vertical profiles were based on both satellite-based CCN estimates near Houston on 19 June 2013 via the methodology described in Rosenfeld et al. (2012), as well as in situ aerosol observations in the boundary layer and free troposphere from aircraft during the Deriving Information on Surface conditions from Column and Vertically Resolved Observations Relevant to Air Quality (DISCOVER-AQ) field campaign, which had operations near Houston, in September 2013 (NASA LARC 2014; Sawamura et al. 2017). In addition to the aerosol number concentration profiles, uniform aerosol number size distributions were also specified using a lognormal distribution with a geometric mean diameter of $100 \mathrm{~nm}$, a geometric standard deviation of $1.8 \mathrm{~nm}$, and a uniform hygroscopicity parameter (i.e., from Petters and Kreidenweis 2007) of 0.2. These aerosol distribution characteristics were also based on data from DISCOVER-AQ. Aerosol number concentrations were initialized in a horizontally homogenous manner across all the model domains at the beginning of each simulation. With the weak synoptic-scale winds during this event and the focus on domain 3, lateral boundary aerosol conditions were unnecessary along the outermost domain (domain 1). The aerosol field was allowed to evolve through processes such as advection, including one-way advection between domains, diffusion, activation, and wet deposition if the models had these processes available (appendix A). Furthermore, aerosol particles were restricted from interacting with radiation in order to isolate the microphysical effects. The manner in which each model parameterized ice nucleation was also kept constant between the Low-CCN and High-CCN simulations (appendix A).

\section{c. Models}

Seven models participated in the ACPC MIP (Table 2). Several important differences between these models are highlighted here, with additional details presented in appendix A. First, six of the models utilized two-moment (2M) bulk microphysical parameterizations with varying levels of sophistication, whereas WRF-SBM used a spectral bin microphysics scheme with recent updates as detailed in Shpund et al. (2019). (a) Simulation Domains (All)

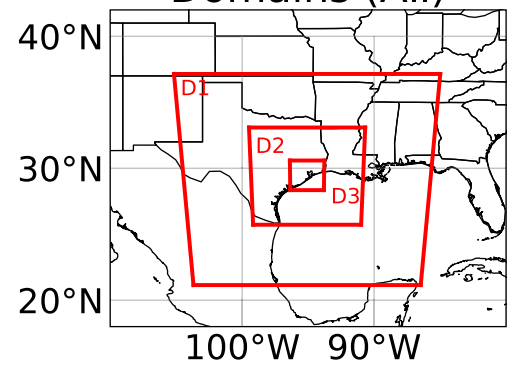

(b) Simulation Domains 2 and 3

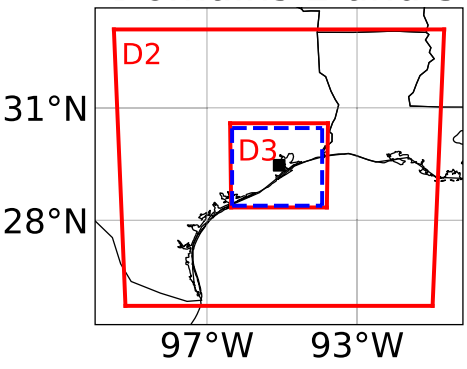

(c) CCN Profiles at Initialization

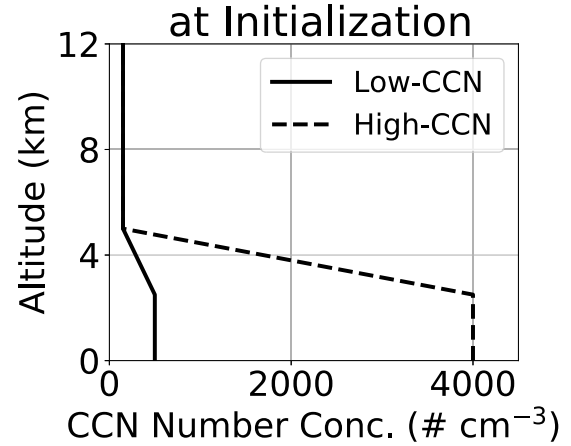

FIG. 3. (a) All three ACPC simulation nested domains. (b) ACPC simulation domains 2 and 3, with the Houston NEXRAD location(KHGX; black square). All analysis computed within a subset of domain 3 (blue dashed line) in order to avoid boundary-impacted model grid cells. (c) Horizontally homogeneous aerosol initialization profiles for the Low-CCN and High-CCN simulations. 
TABLE 2. Participating models in the ACPC MIP.

\begin{tabular}{|c|c|c|c|}
\hline Model & Abbreviation & Primary reference(s) & Contributing institution \\
\hline $\begin{array}{l}\text { Consortium for Small-Scale } \\
\text { Modeling, v5.1 }\end{array}$ & COSMO & Schättler et al. (2019) & Karlsruhe Institute of Technology \\
\hline MesoNH Model, v5.4.1 & MesoNH & Lac et al. (2018) & Météo-France \\
\hline $\begin{array}{l}\text { Regional Atmospheric Modeling } \\
\text { System, v6.2.09 }\end{array}$ & RAMS & $\begin{array}{l}\text { Cotton et al. (2003), Saleeby and van } \\
\text { den Heever (2013) }\end{array}$ & Colorado State University \\
\hline Unified Model, v.10.8 & UM & Walters et al. (2017) & University of Leeds \\
\hline $\begin{array}{l}\text { NASA Unified Weather Research and } \\
\text { Forecasting (WRF) Model, v3.9.1 }\end{array}$ & NU-WRF & $\begin{array}{l}\text { Skamarock et al. (2008), Peters-Lidard } \\
\text { et al. (2015) }\end{array}$ & NASA \\
\hline WRF, v3.7.1, with Morrison microphysics & WRF-Morr & Skamarock et al. (2008) & University of Oxford \\
\hline $\begin{array}{l}\text { WRF, v4.0.3, with Hebrew University } \\
\text { Cloud Model bin microphysics }\end{array}$ & WRF-SBM & Skamarock et al. (2008) & Pacific Northwest National Laboratory \\
\hline
\end{tabular}

Three models either prognose or diagnose supersaturation (RAMS, NU-WRF, WRF-SBM), while the other four models utilize saturation adjustment - a model process in which any liquid supersaturation that develops at a model grid point is completely eliminated at each time step via condensation onto already formed hydrometeors. The use of saturation adjustment in microphysics schemes has been shown to weaken the response of deep convective updrafts to varying $\mathrm{CCN}$ concentrations (e.g., Khain and Lynn 2009; Lebo et al. 2012).

All of the models represent aerosol activation, although via different formulations (appendix A). Two models (COSMO, WRF-Morr) have fixed aerosol profiles, while the other five models allow aerosol particles to be advected by the wind. Therefore, the aerosol concentrations within domain 3 vary in part due to the amount of aerosol advected between the domains in each simulation. The latter five models also have differences in terms of their aerosol sources and sinks (e.g., aerosol regeneration via evaporation and sublimation, activation sinks, wet and dry deposition). These aerosol sinks and sources can have impacts on interpreting aerosol effects in deep convective clouds (e.g., Seifert et al. 2006; Fan et al. 2012). Because of the differences in the parameterization of aerosol processes, the $\mathrm{CCN}$ concentrations evolve differently in the five models (Fig. 4, left and middle columns). However, the relative differences between the High-CCN and Low-CCN simulations among the models are similar (Fig. 4, right column). High-CCN simulations from the five models have, on average over the 12-h analysis period, $\sim 7.0-7.5$ times more particles than the Low-CCN simulations from 0 to $2 \mathrm{~km}$ above ground level (AGL), while the two models with fixed aerosol profiles have 8.0 times as many particles (Fig. 3c).

Three of the ACPC MIP participants were unable to ingest the Global Data Assimilation System Final (GDAS-FNL) analysis data for their initial and lateral boundary conditions (COSMO, UM, MesoNH) and therefore used other atmospheric analysis datasets (appendix A). To assess how the environmental conditions evolve in each simulation, the mixed-layer (lowest $500 \mathrm{~m}$ AGL) convective available potential energy (MLCAPE), mixed-layer convective inhibition (MLCIN), and wind shear over a depth of 2-10 km AGL are calculated for the different simulations (Figs. 5a-c) from base-state profiles, which are computed by utilizing the noncloudy grid points (i.e., grid points with total condensate $<0.1 \mathrm{~g} \mathrm{~kg}^{-1}$ ) within the simulation's innermost domain (see appendix B for more details on the base-state calculations). The base state profiles for potential temperature and water vapor mixing ratio, averaged over the 12 -h period, are also shown in Figs. 5d and 5e. Due to the environmental evolution within each model, the atmospheric parameters, particularly MLCAPE (Figs. 5a,d), have a wide range among the models, even among those models that used the same initialization dataset. These differences in atmospheric stability (e.g., CAPE) can modulate the impacts of CCN on deep convection.

Furthermore, differences between the models under the same aerosol scenario are much larger than differences between each model's High-CCN and Low-CCN simulations, demonstrating that differences in model parameterizations, dynamical cores and/or initial and lateral boundary data play a more significant role in altering the evolution of the atmosphere, compared to the differences in the aerosol concentrations tested in this study. Over the 12-h analysis period, the mean MLCAPE, MLCIN and wind shear for the same aerosol scenario have percentage differences between the models as high as $49 \%, 550 \%$, and $35 \%$, respectively. However, the MLCAPE percentage differences between the High-CCN and Low-CCN simulations for each model are, on average, within $4 \%$ (Figs. 5a,f). These relatively small differences in MLCAPE are in part due to counteracting changes in the boundary layer temperature and moisture (Figs. 5i,j). All the models have lower MLCIN (2.1\%-9.6\%) in the Low-CCN simulations (Figs. 5b,e), which is likely associated with more boundary layer moisture from more widespread precipitation (Fig. $5 \mathrm{j}$ ). In terms of the wind shear (Figs. $5 \mathrm{c}, \mathrm{h}$ ), all models have, on average, slightly stronger $(0.7 \%-5.2 \%)$ wind shear in the High-CCN simulations, with the majority of models falling within $2 \%$.

While the preceding paragraphs have focused on comparisons of the model and simulation characteristics that have been shown to modulate the impacts of aerosol particles on deep convective cloud updrafts in previous research, each model is also integrated with various other physical parameterizations (e.g., surface, radiation, and turbulence; see appendix A) that might impact the model solution. Due to the many differences in the models, it is difficult to attribute the variability in the $\mathrm{CCN}$ effects to specific microphysical and/or aerosol parameterizations and processes; rather, the goal of this study is to 
High-CCN $\left(\# \mathrm{~cm}^{-3}\right)$ (a) MesoNH

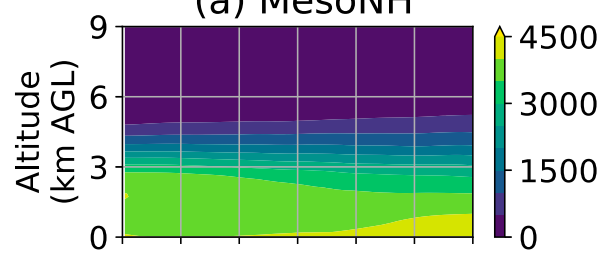

(d) RAMS

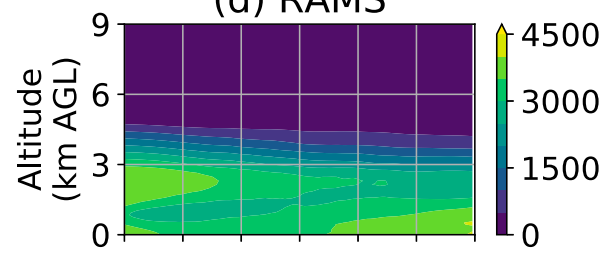

(g) UM

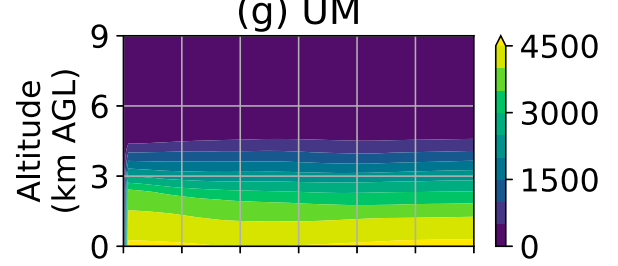

(j) NU-WRF
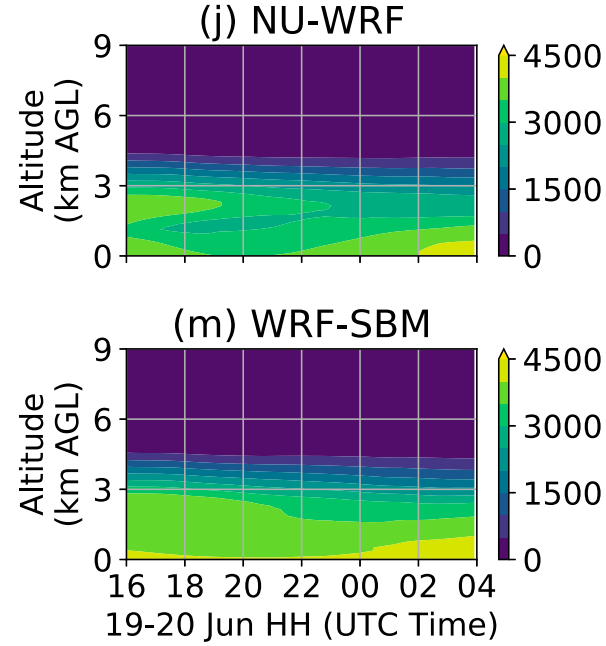

Low-CCN $\left(\# \mathrm{~cm}^{-3}\right)$

(b) MesoNH

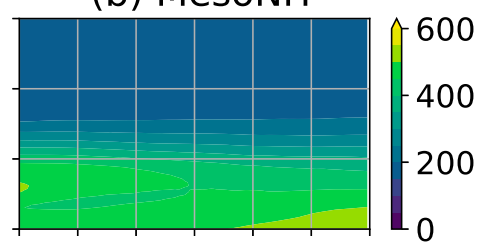

(e) RAMS

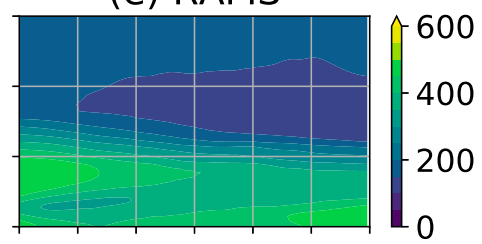

(h) UM

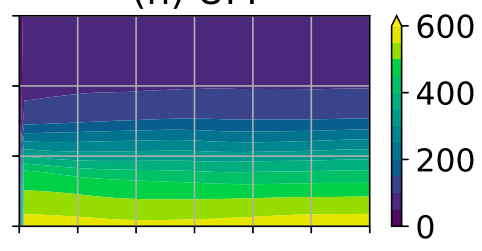

(k) NU-WRF

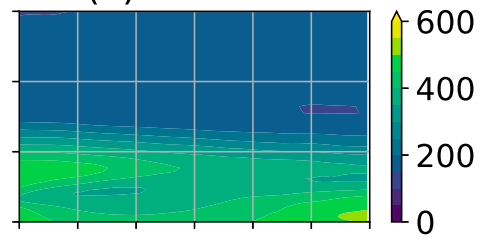

(n) WRF-SBM

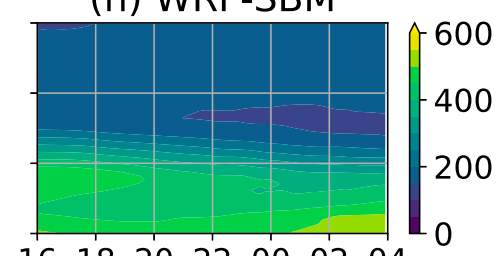

$\begin{array}{lllllll}16 & 18 & 20 & 22 & 00 & 02 & 04\end{array}$ 19-20 Jun HH (UTC Time)
[High-Low]/[Low] (\%)

(c) MesoNH

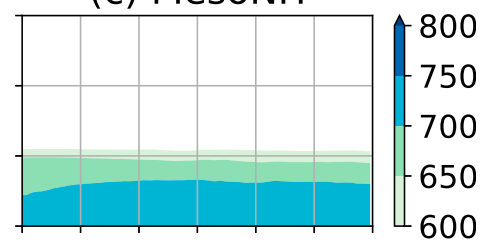

(f) RAMS

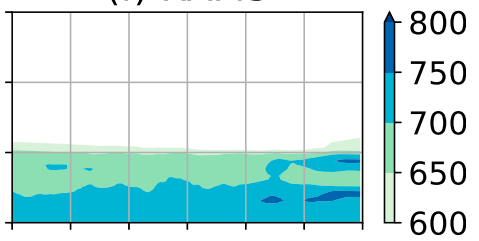

(i) UM

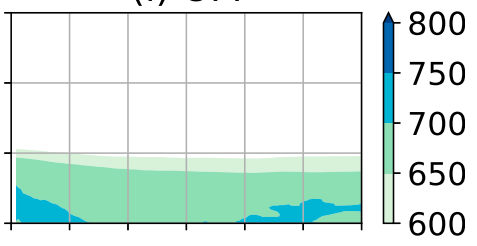

(I) NU-WRF

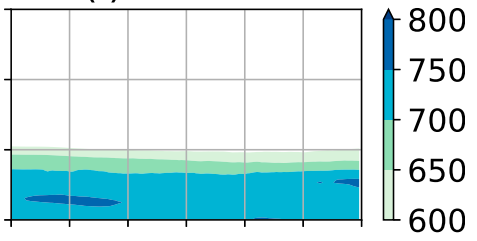

(o) WRF-SBM

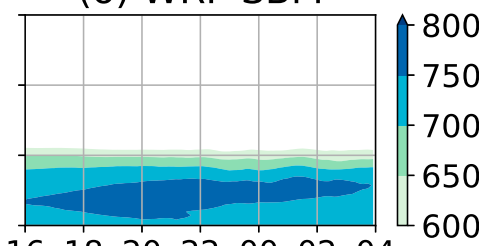

$\begin{array}{lllllll}16 & 18 & 20 & 22 & 00 & 02 & 04\end{array}$

19-20 June HH (UTC Time)

FIG. 4. Evolution of mean aerosol concentration profiles in (left) the High-CCN simulation, (center) the Low-CCN simulation, and (right) the percentage difference of High-CCN from Low-CCN. Values represent averages over the noncloudy grid points within domain 3. Models with fixed aerosol profiles throughout the simulation (COSMO, WRF-Morr) are not shown. Note the difference in scales between the High-CCN and Low-CCN columns.

quantify the spread in the CCN effects on convective updrafts from various community-developed cloud-resolving models in their typical, standard model configurations and subsequently to present the consistent and inconsistent updraft trends.

Despite these model differences, all the models produce scattered deep convective clouds near Houston in both the High-CCN and Low-CCN simulations during the 12-h period (Fig. 6), albeit with different timing and frequencies, which can be partly explained by the varying environmental conditions among the models. In this study, deep convective updrafts are determined as follows. All simulation data are screened to only include grid points between 2 and $14 \mathrm{~km}$ AGL that were within a 6-km-deep (or deeper) column of cloudy conditions (i.e., have total condensate mixing ratio $>0.1 \mathrm{~g} \mathrm{~kg}^{-1}$ ) and of continuous vertical velocities that are all greater than $3 \mathrm{~m} \mathrm{~s}^{-1}$. Several additional vertical velocity thresholds $\left(1-5 \mathrm{~m} \mathrm{~s}^{-1}\right)$ and depths $(4-7 \mathrm{~km})$ were also considered, tested, and found to produce qualitatively similar results. While there are differences in the timing and longevity of the periods when deep convective clouds are present among the models, the convective cloud 

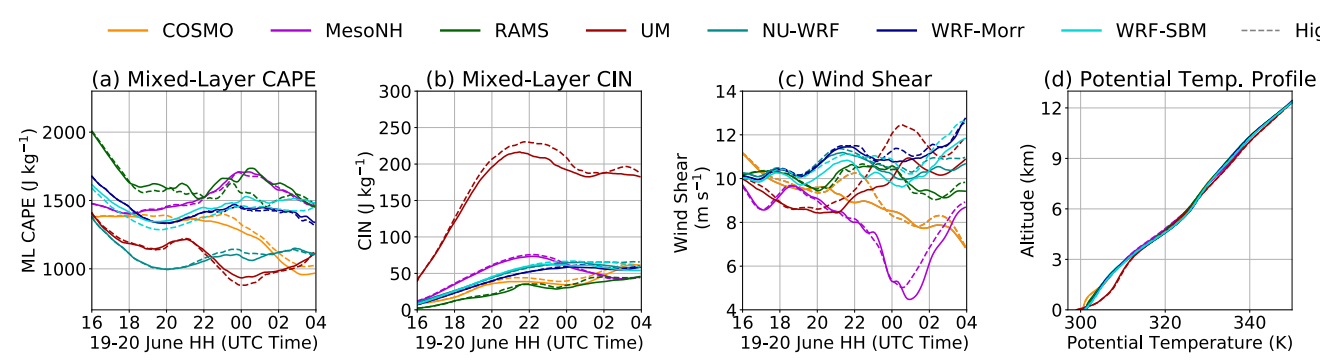

High-CCN L Low-CCN
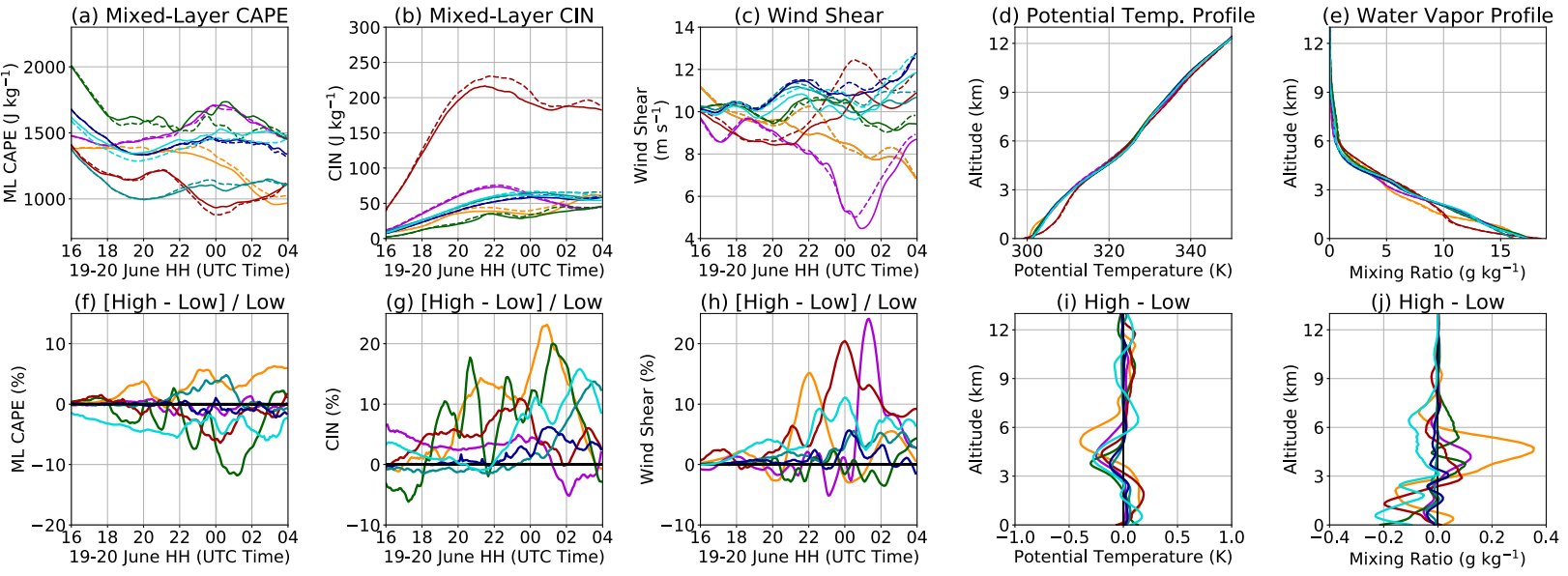

FIG. 5. Evolution of (a) mixed-layer (500 m AGL) convective available potential energy (MLCAPE), (b) mixed-layer convective inhibition (CIN), and (c) 2-10-km-layer wind shear in the High-CCN (dashed) and Low-CCN (solid) simulations. (d), (e) The base-state potential temperature and water vapor mixing ratio profiles averaged over the 12-h period in the High-CCN (dashed) and Low-CCN (solid) simulations. (f)-(h) The percentage differences between the High-CCN and Low-CCN simulations for the variables in (a)-(c), respectively. (i),(j) The differences between the High-CCN and Low-CCN simulations in (d) and (e), respectively.

periods are similar in the High-CCN and Low-CCN simulations for each individual model, highlighting again that varying $\mathrm{CCN}$ concentrations in each model does not affect the initiation and life cycle of deep convection as much as the differences in the model parameterizations, dynamical cores, and initialization datasets. Of note, the COSMO, UM, and NUWRF models produce less and/or generally weaker convection than the other models, while the RAMS, MesoNH, and WRFSBM models produce longer periods of and more intense deep convection (Fig. 6), consistent with the models' environmental stability (Fig. 5). Using these identified deep convective cloud updrafts, their differences under the High-CCN and Low-CCN conditions will now be assessed.

\section{CCN effects on the deep convective updrafts}

\section{a. Frequency}

To assess the variations in the amount and vertical distribution of the deep convective updrafts in the High-CCN and Low-CCN simulations, the frequency of the identified deep convective updraft grid points, as a function of height and updraft magnitude are shown in Fig. 7. Three of the seven models (UM, NU-WRF, WRF-Morr) simulate larger amounts (number and/or size) of deep convective updrafts for most of the updraft magnitudes in the High-CCN simulations compared to the Low-CCN simulations (Figs. 7o-u). These mixed results among the models are most likely related to the differences in the environmental conditions and feedback processes that trigger new convection, such as cold pools. The two models with the smallest response in the deep convective updraft amounts (MesoNH, RAMS) also have the largest MLCAPE values and longest periods of deep convective clouds (Figs. 5a and 6), suggesting that deep convective updraft amounts in higher MLCAPE environments are more influenced by thermodynamics than by
CCN concentrations. Alternatively, the UM simulations, which had the largest increase between the High-CCN and Low-CCN cases, also had much higher MLCIN than the other models, as well as lower MLCAPE, which may reflect an environmental regime where convection initiation and development is more sensitive to varying $\mathrm{CCN}$. Also, three of the models that show decreases in convective updraft amounts in the High-CCN simulations (COSMO, RAMS, WRF-SBM) also produce weaker cold pools in the High-CCN simulations (not shown), which would lead to weaker feedbacks to cloud and updraft initiation.

\section{b. Intensity}

The mean vertical velocity profiles within the simulated deep convective updrafts, the percentage difference between the High-CCN and Low-CCN profiles, and the numbers of convective updraft grid points that were identified and used in this analysis are shown in Figs. 8a-c. First, the mean profiles for all the model simulations have similar shapes, generally peaking at 9-10 km AGL, suggesting that comparable updrafts are being assessed, both between the models and between the High-CCN and Low-CCN simulations (Fig. 8a). Throughout the depth of the updrafts, the changes in the mean updraft magnitudes (High - Low) were generally small (between $-5 \%$ and $+15 \%$ ), suggesting that the mean response over several hours and many convective cells may be subdued due to feedback processes and the variability in convective cell development. All the models produce neutral-to-stronger updrafts ( $\sim 5 \%$ to $15 \%$ ) between 4 and $7 \mathrm{~km}$ AGL in the HighCCN simulations compared with their Low-CCN counterparts (Fig. 8b), with the median model response around $+10 \%$. Some of the strongest responses occurred in the models with the lowest MLCAPE values (COSMO, UM, NU-WRF), and some of the weakest responses occurred in models with higher MLCAPE values (MesoNH, RAMS). The models with the 
High-CCN

(a) COSMO

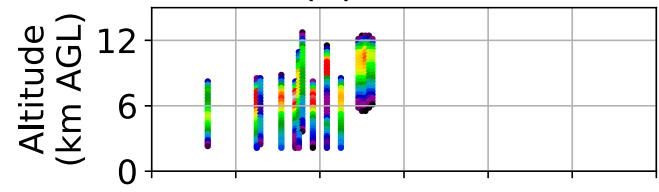

(c) MesoNH

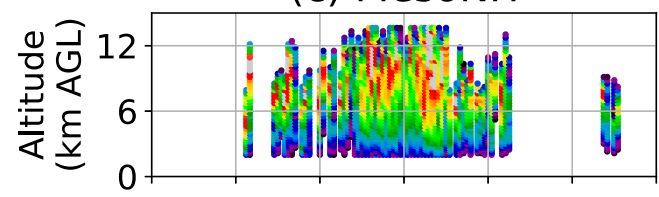

(e) RAMS

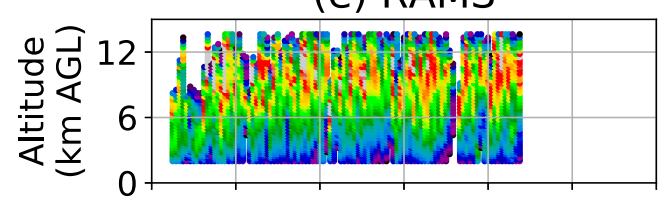

(g) UM

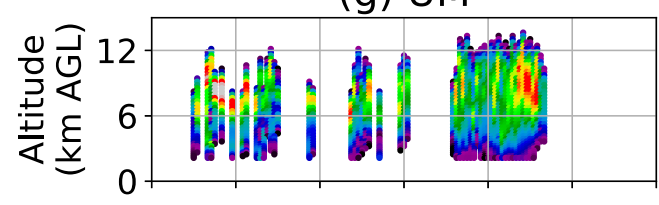

(i) NU-WRF

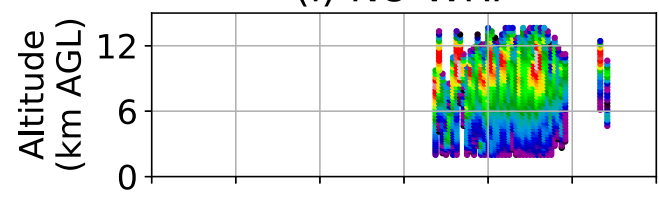

(k) WRF-Morr

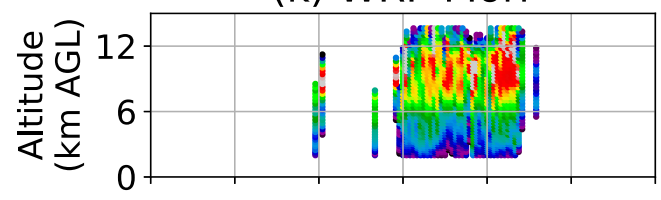

(m) WRF-SBM

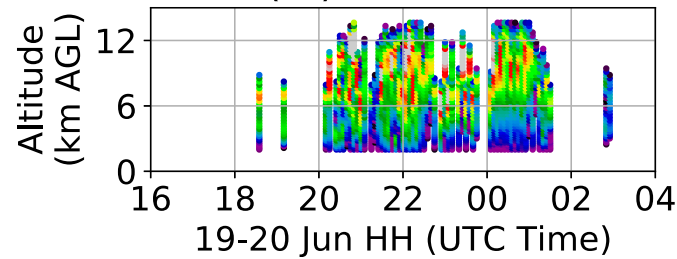

Low-CCN

(b) COSMO

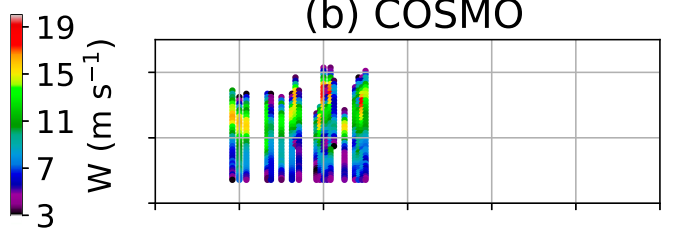

(d) MesoNH

$\mid \begin{aligned} & 19 \\ & 15 \\ & 11 \\ & 11 \\ & 7 \\ & 3\end{aligned}$

19
$15 \hat{\imath}$
-11
-7
3
3

(f) RAMS

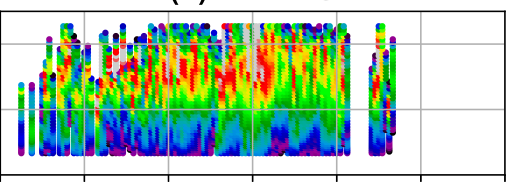

(h) UM
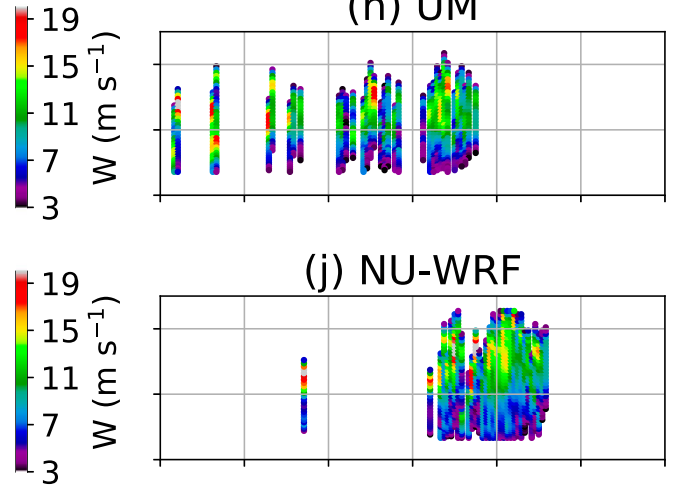

(I) WRF-Morr

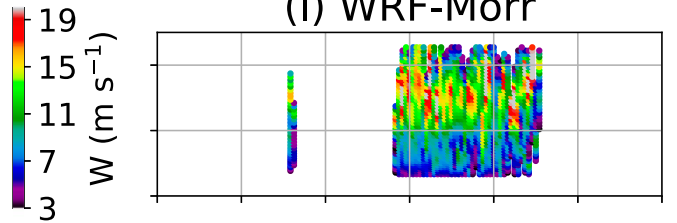

(n) WRF-SBM

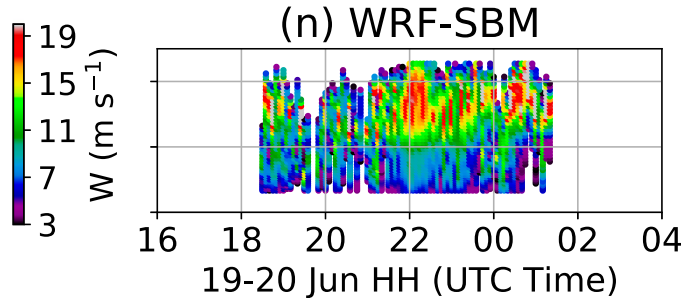

FIG. 6. Temporal evolution of updraft velocities for deep convective columns, as defined in the text and averaged at each output time, for the (left) High-CCN and (right) Low-CCN simulations.

lowest MLCAPE values also had fewer deep convective updraft amounts (Fig. 8c). The signal of more intense updrafts in the High-CCN simulations wanes in the majority of the models above $\sim 5 \mathrm{~km}$ AGL through to $\sim 8 \mathrm{~km}$ AGL. Above $8 \mathrm{~km}$ AGL through to $\sim 11 \mathrm{~km}$ AGL, the High-CCN simulation mean updraft velocities remains stronger $(\sim+5 \%$ to $15 \%)$ as compared to the Low-CCN simulation in three of the models (UM, NU-WRF, WRF-Morr), while the other four models have 

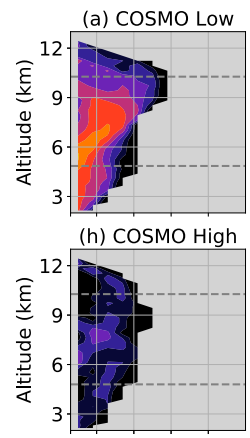

(o) (High-Low)/Low

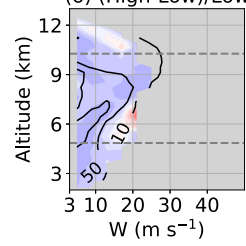

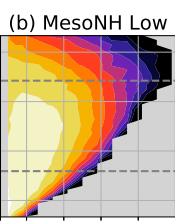

(i) MesoNH High
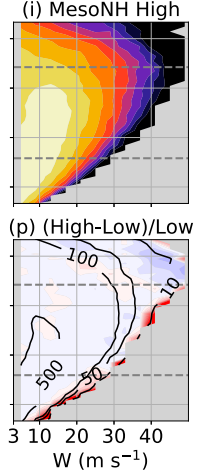
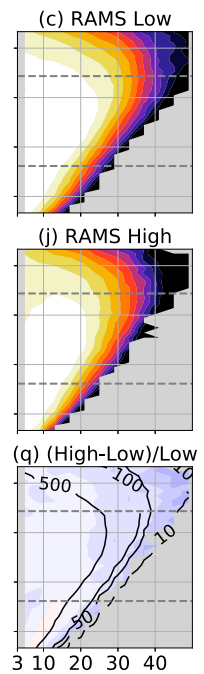

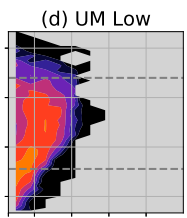

(k) UM High

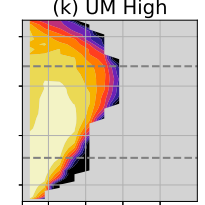

(r) (High-Low)/Low

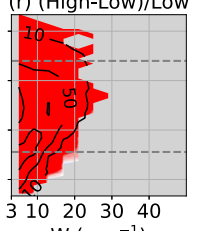

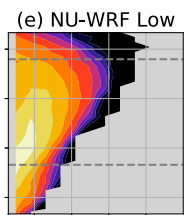

(I) NU-WRF High
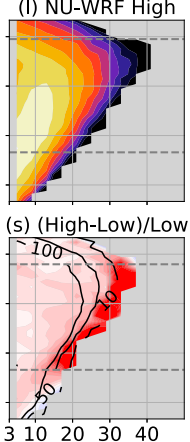

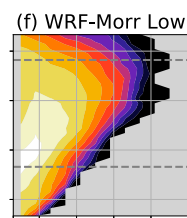

(m) WRF-Morr High
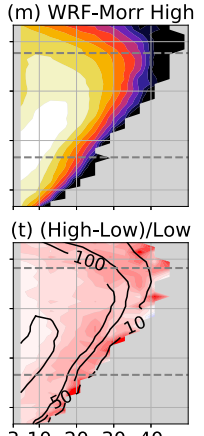

310203040 $\mathrm{W}\left(\mathrm{m} \mathrm{s}^{-1}\right)$

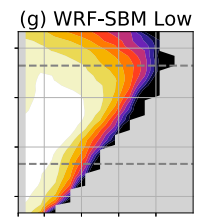

(n) WRF-SBM High
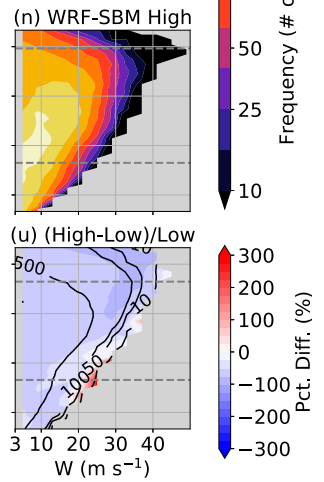

FIG. 7. Frequency of deep convective updraft grid points, as defined in the text, as a function of height and updraft magnitude. These panels are similar to contour frequency by altitude diagrams (CFADs; see Fig. 9), except that they are not normalized. (a)-(g) The LowCCN simulations, (h)-(n) the High-CCN simulations, and (o)-(u) the percentage difference of the High-CCN from the Low-CCN simulations. In (o)-(u), results are only shown when data are available for both the High-CCN and Low-CCN simulations. The black contours in $(\mathrm{o})-(\mathrm{u})$ are the frequency counts from the Low-CCN simulations for each model and are plotted for reference. The data are binned at $4 \mathrm{~m} \mathrm{~s}^{-1}$ intervals, starting at $3 \mathrm{~m} \mathrm{~s}^{-1}$. The gray dashed lines represent the altitudes where the base-state profile temperatures are $0^{\circ}$ and $-38^{\circ} \mathrm{C}$, respectively.

neutral-to-weaker $(\sim-5 \%$ to $0 \%)$ mean vertical velocities in the High-CCN simulations. These models with the stronger mean updraft velocities also have more ice mass above $6.0 \mathrm{~km}$ AGL (not shown). For completeness, the percentage differences in the 50th (median), 75th, and 90th percentiles are included in Figs. 8d-f and show similar trends to the mean values for all of the models with the exception of above $9 \mathrm{~km}$ AGL in COSMO, which is likely related to the smaller sample of deep convective updrafts in COSMO. The remainder of this manuscript therefore focuses on the mean trends.

To better understand the trends in the mean deep convective updraft magnitudes, contoured frequency by altitude diagrams (CFADs; Yuter and Houze 1995) are calculated by dividing the frequency counts (Fig. 7) by the sum of the total number of counts at each altitude level, which eliminates the dependence on absolute number and thus can be used to more easily compare the shapes of the vertical velocity distributions at each altitude (Fig. 9). All of the models demonstrate a shift to more frequent occurrences of the stronger updrafts and less frequent occurrences of the weaker updrafts in the High-CCN simulations from $\sim 4$ to $7 \mathrm{~km}$ AGL (Figs. 9o-u), consistent with the stronger mean vertical velocities (Fig. 8b); although RAMS and, to a lesser extent, UM have fewer of the most intense vertical velocities at these altitudes. The three models that clearly demonstrate this shift throughout the depth of the convective updrafts (UM, NU-WRF, WRF-Morr; Figs. 9r-t) also have stronger mean updrafts above $7 \mathrm{~km}$ AGL in the High-CCN simulations (Fig. 8b). The other four models (COSMO, MesoNH, RAMS, WRF-SBM), which have weaker-to-neutral mean updrafts above $7 \mathrm{~km}$ AGL in the High-CCN simulations (Fig. 8b), depict a reversal in the CFAD differences in the middle- and upper-tropospheric levels (Figs. 9o-q,u). This reversal may be related to these models' higher MLCAPE values, as compared to NU-WRF and UM (Fig. 5a). To better understand the physical processes that are associated with these updraft responses to the varying $\mathrm{CCN}$ concentrations, the terms of the vertical velocity tendency equation are assessed.

\section{Vertical velocity tendency equation and terms}

Each model utilizes different prognostic variables and approximations to predict how the vertical velocity $(w)$ changes with time during the model integration. Because each model's representation and calculation of the vertical momentum equation are different, we use a basic form of the vertical momentum equation [Eq. (1)] and approximate the various terms for each model's native grid and standard variable outputs:

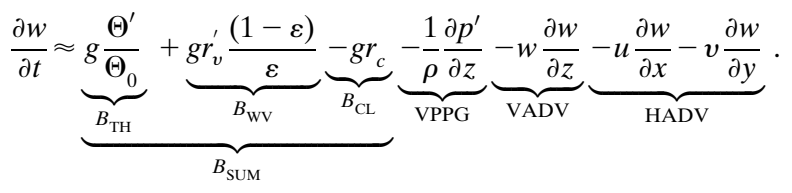

In Eq. (1), the term on the left-hand side is the local time derivative of $w$, which represents how $w$ changes with each model time step at each grid point. On the right-hand side (rhs), the first three terms represent the buoyancy $(B)$ acceleration terms. The first rhs term is the buoyancy acceleration associated with changes in temperature, where $\Theta^{\prime}$ is the perturbation 
(a) Mean Convective Column W

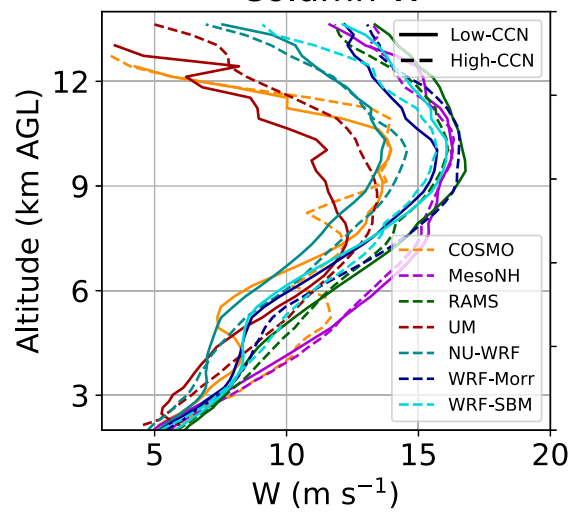

(d) Percent Diff. in $50^{\text {th }}$ [High - Low] / Low

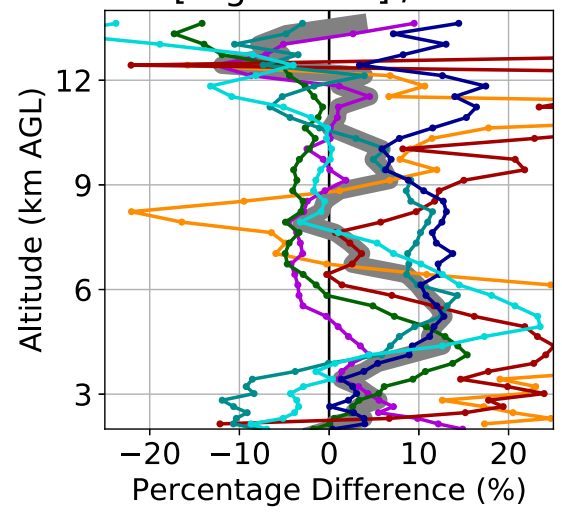

(b) Percent Diff. in Mean [High - Low] / Low

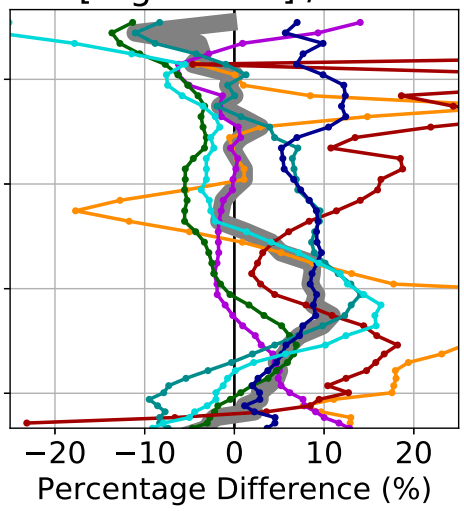

(e) Percent Diff. in $75^{\text {th }}$ [High - Low] / Low

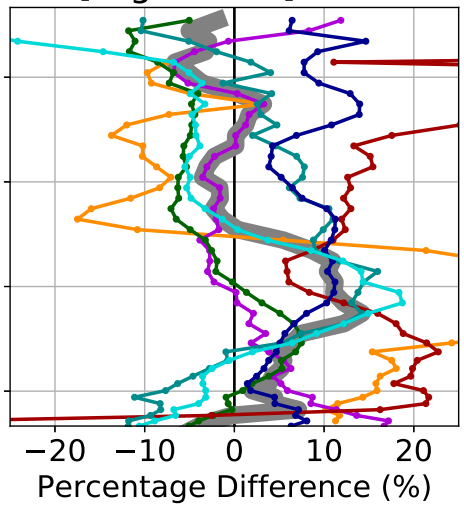

(c) Number of Grid Points

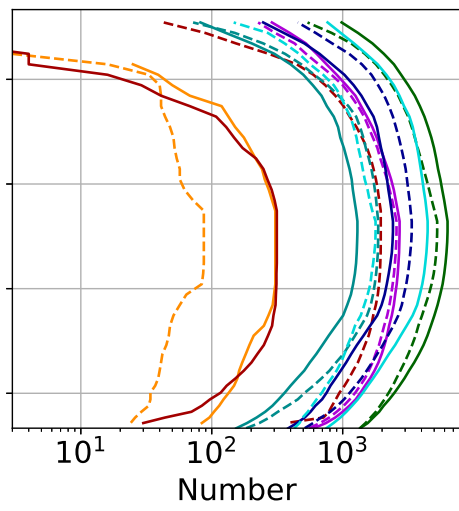

(f) Percent Diff. in $90^{\text {th }}$ [High - Low] / Low

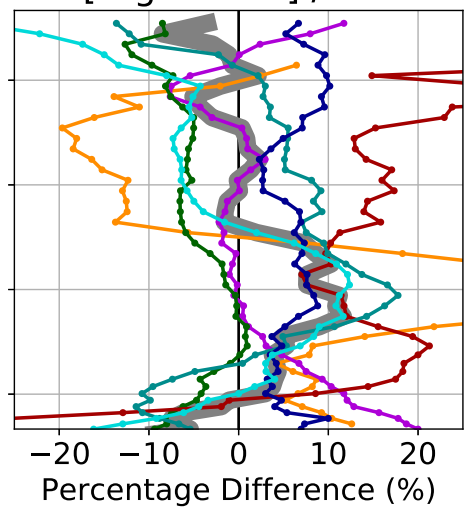

FIG. 8. (a) Profiles of mean vertical velocities over deep convective updrafts in all the simulations. The solid lines represent the LowCCN simulations, and the dashed lines represent the High-CCN simulations. (b) Vertical profiles of the percent difference in the HighCCN simulations' mean vertical velocities from the Low-CCN simulations' mean vertical velocities, as shown in (a). (c) The number of grid points used for these calculations. (d)-(f) As in (b), but for the 50th, 75th, and 90th percentiles, respectively. The thick, gray lines in (b) and (d)-(f) represent the median response among the seven models.

potential temperature, $\Theta_{0}$ is the base-state potential temperature, and $g$ is the gravitational acceleration of $9.8065 \mathrm{~m} \mathrm{~s}^{-1}$. The second rhs term is the buoyancy acceleration associated with changes in the amounts of water vapor in the air, where $r_{v}^{\prime}$ is the perturbation water vapor mixing ratio, and $\varepsilon$ is the ratio of dry air to water vapor gas constants $(\sim 0.622)$. The third rhs term is the buoyancy acceleration associated with the amount of water condensate mass, where $r_{c}$ is the total condensate mixing ratio. These three terms, when summed, represent the net buoyancy acceleration $\left(B_{\mathrm{SUM}}\right)$ and have been the primary focus of most assessments of aerosol effects on deep convective updrafts (e.g., Khain et al. 2005; Rosenfeld et al. 2008; Lebo and Seinfeld 2011; Storer and van den Heever 2013).

The fourth rhs term is the vertical perturbation pressure gradient (VPPG) acceleration, where $\rho$ is the air density, and $\partial p^{\prime} / \partial z$ is the vertical gradient in the perturbation pressure. The fifth rhs term is the acceleration due to vertical advection (VADV), where $\partial w / \partial z$ is the vertical gradient in $w$. Finally, the last two terms on the rhs of Eq. (1) represent the acceleration due to horizontal advection (HADV), where $u$ and $v$ are the zonal and meridional wind components, and $\partial w / \partial x$ and $\partial w / \partial y$ are the horizontal gradients in $w$. Typically, Eq. (1) would also include a diffusion term, but because of the larger discrepancies on how diffusion is represented in these models, the diffusion term is not considered in this study. It is expected that this diffusion term is relatively small, both in terms of its actual magnitude and in terms of differences between the High-CCN and Low-CCN cases within the composited deep convective updrafts cores assessed in this study, and therefore, will not impact the interpretation of these results.

Some of the terms in Eq. (1) require a perturbation and/or base-state variable. This perturbation value is calculated by subtracting a time-varying, altitude-dependent base-state value from the full variable value. A base-state profile was calculated for each simulation as an average of the noncloudy grid points (total condensate $<0.1 \mathrm{~g} \mathrm{~kg}^{-1}$ ) at the varying model altitudes. Additional details on base-state profile calculations are provided in appendix B. 

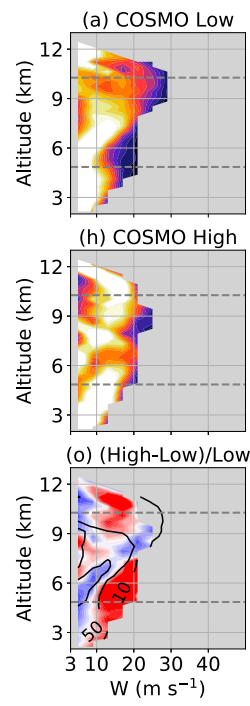
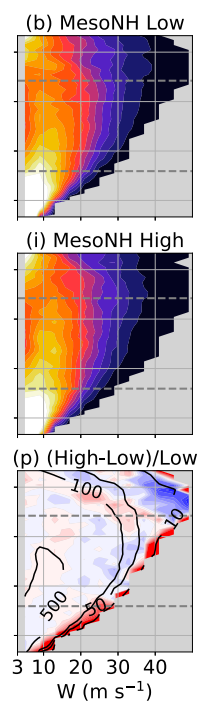

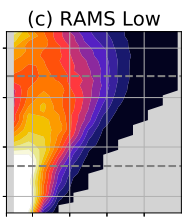

(j) RAMS High
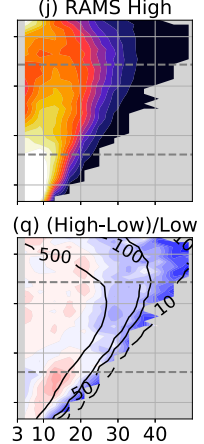

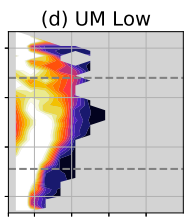

(k) UM High

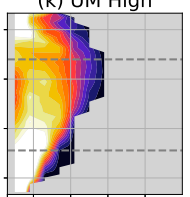

(r) (High-Low)/Low

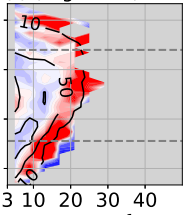

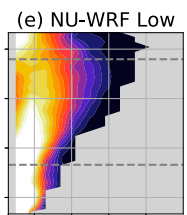

(I) NU-WRF High
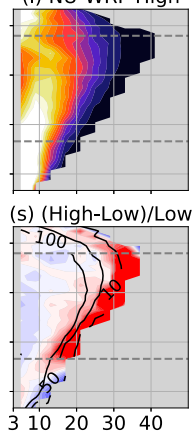

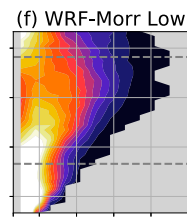

(m) WRF-Morr High
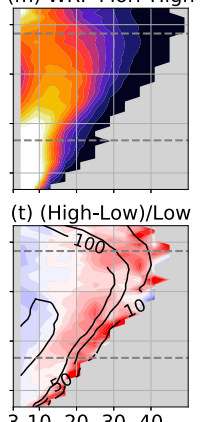

310203040

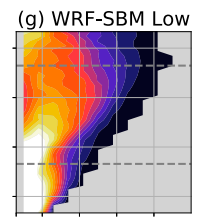

(n) WRF-SBM High
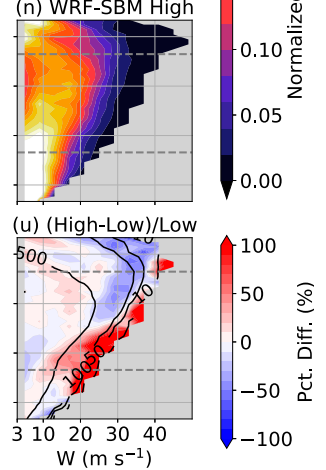

FIG. 9. CFADs of vertical velocities within the deep convective updrafts, as defined in the text. As in Fig. 7, except that the frequencies are normalized for the total number of grid points at that altitude.

To compare these approximations of the $w$ tendency equation terms to the online model prediction of $w$, a brief closure assessment was conducted. For one of the models (RAMS), the model data were outputted for three consecutive model times $(t-3 \mathrm{~s}, t, t+3 \mathrm{~s}$; the time step is $3 \mathrm{~s})$, such that an accurate approximation of $\partial w / \partial t$ could be made using a centered-in-time difference at time $t$. Each of the terms from Eq. (1) was calculated at time $t$, based on the approach described in the preceding paragraphs. Figures 10a-g show these various term calculations for a horizontal slice through a deep convective updraft at $7.6 \mathrm{~km}$ AGL. The terms have varying signs and distributions within the updraft. The sum of the terms [rhs of Eq. (1); Fig. 10h] is compared to the $\partial w / \partial t$, which is calculated from the $w$ field in the model (Fig. 10i) at times $t+3 \mathrm{~s}$ and $t-3 \mathrm{~s}$. The residual from this comparison (Fig. 10j) is much smaller than the sum of the terms (Fig. 10h) and most of the individual terms (Figs. 10a-g). The largest residual values are present along the strongest horizontal gradients in $w$ (Fig. 10j), which is likely related to the exclusion of the diffusion term which would have the strongest impacts in these high-gradient regions. Although Fig. 10 only depicts one horizontal slice through one convective updraft in one of the models, this closure was calculated for all the cloudy updrafts at this time with the RAMS model output and produced similar results. This closure exercise therefore demonstrates that the terms of the $w$ tendency equation [Eq. (1)] can be accurately calculated in this manner using the simulation output. In the following sections, we compare these terms in the High-CCN and Low-CCN simulations for all the models in order to explain the trends in the mean updrafts.

\section{a. Thermal buoyancy $\left(B_{\mathrm{TH}}\right)$}

Figure 11 depicts the mean thermal buoyancy term for the deep convective updrafts averaged for each model vertical level and for the $4 \mathrm{~m} \mathrm{~s}^{-1}$ intervals of $w$ (the same bins as in
Figs. 7 and 9). Since all of the terms in Eq. (1) are either directly or indirectly dependent on the magnitude of $w$, this analysis allows for the comparison of the High-CCN and Low-CCN simulations at similar values of $w$.

The thermal buoyancy term $\left(B_{\mathrm{TH}}\right)$ is positive for almost all convective updraft regions (Figs. 11a-n), except for the convective updraft tops (above $\sim 11 \mathrm{~km} \mathrm{AGL}$ ) where entrainment and sublimation are likely to be resulting in cooler temperatures with respect to the environmental base state. When comparing the High-CCN and Low-CCN simulation updrafts (Figs. 11o-u), several patterns emerge. First, between $\sim 2$ and $3 \mathrm{~km}$ AGL, four models (COSMO, RAMS, NU-WRF, WRF-SBM) depict neutral or weaker $B_{\mathrm{TH}}$ in the High-CCN simulations, which may be related to changes in the cloud-base forcing such as cold pools. However, from $\sim 3$ to $5 \mathrm{~km}$ AGL, all models show larger, positive $B_{\mathrm{TH}}$ in the High-CCN simulation, consistent with the stronger updrafts in this region (Fig. 8) and more condensation and latent heat release onto the greater number concentrations of cloud droplets. This robust signal among all the models is surprising, considering that four of the models use saturation adjustment schemes, which cannot accurately represent condensational growth within the supersaturated updrafts that arises due to differences in cloud drop concentrations (e.g., Khain and Lynn 2009; Lebo et al. 2012). This suggests that the robust response of stronger updrafts between 3 and $5 \mathrm{~km}$ in the High-CCN case is partly related to some other similar change in the environment, in the development of these deep convective clouds, and/or microphysical-dynamical feedbacks throughout the 12 -h period. All the models' High-CCN simulations have warmer environmental temperatures from $\sim 0-3 \mathrm{~km}$ AGL due to less precipitation and evaporation. They also have cooler environmental temperatures from $\sim 3-6 \mathrm{~km}$ AGL, in part due to enhanced cloud evaporation (Fig. 5i), which leads to higher instability and thermal buoyancy in the clouds between $\sim 3-6 \mathrm{~km}$ AGL in the High-CCN case. We suspect that 
(a) $\mathrm{B}_{T H}$

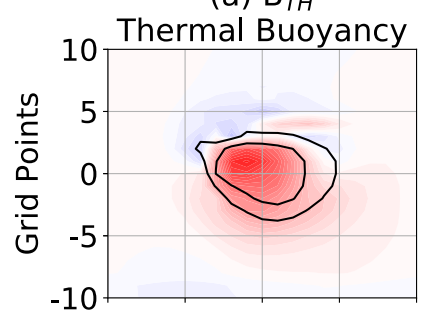

(e) VPPG

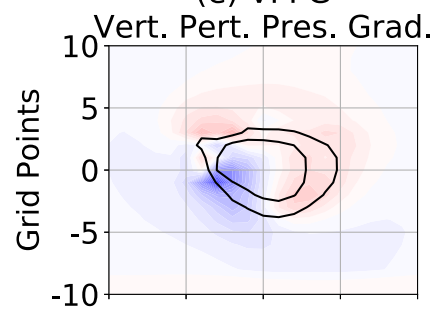

(h) $\delta w / \delta t$ Estimate $\operatorname{sum}(d-f)$

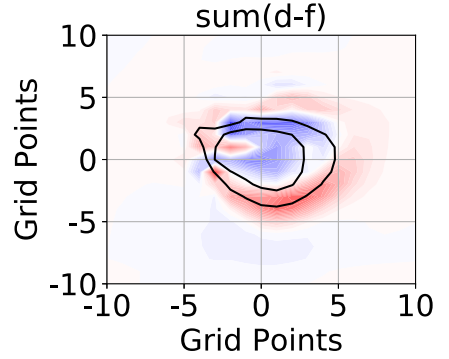

(b) $\mathrm{B}_{Q V}$ Moisture Buoyancy

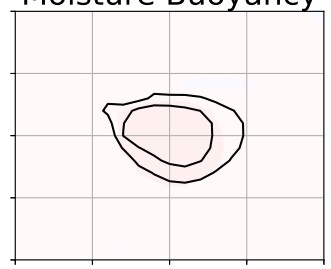

(f) VADV
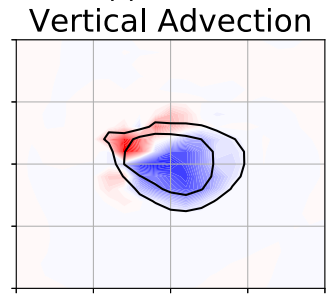

(i) $\delta w / \delta t$

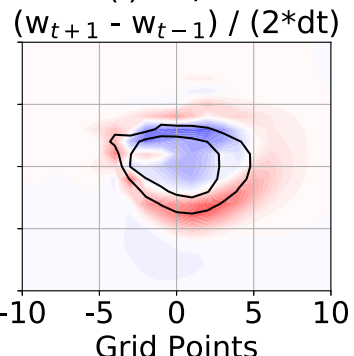

(c) $B_{C L}$

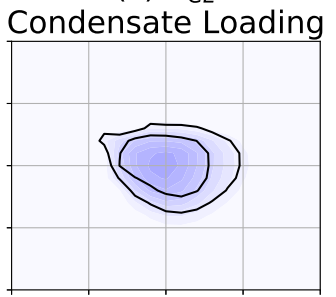

(g) HADV

Horizontal Advection

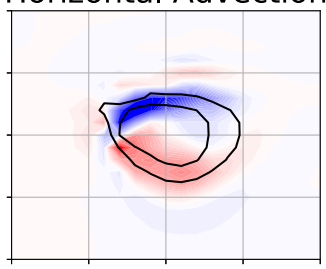

(j) $\delta w / \delta t$ Residual

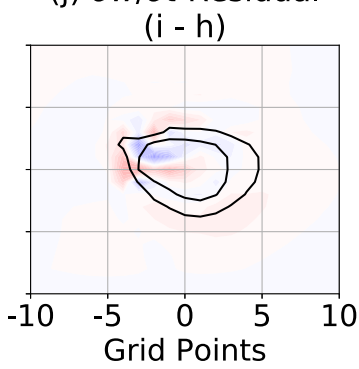

(d) Bsum
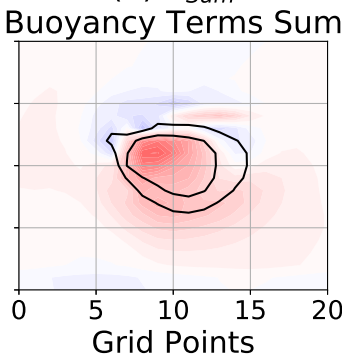

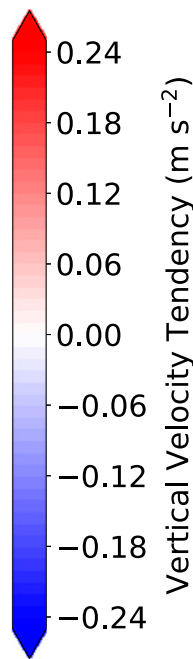

FIG. 10. Horizontal slice at 7.6 km AGL through a deep convective cloud from the RAMS Low-CCN simulation at 2100:03 UTC. (a)-(g) The vertical velocity tendency terms in Eq. (1), using the approach defined in the text. (h) The sum of these terms, which represents an estimate of $\partial w / \partial t$. (i) $\partial w / \partial t$, estimated using centered-in-time differencing from the model $w$ from the time steps directly before and after 2100:03 UTC. (j) The residual in $\partial w / \partial t$ [(i) minus (h)]. The black contours represent vertical velocities of 3 and $15 \mathrm{~m} \mathrm{~s}^{-1}$.

this change in stability is partly driving the robust updraft response between $\sim 4$ and $7 \mathrm{~km}$ AGL (Fig. 8b). Directly above this region of more intense, positive $B_{\mathrm{TH}}(\sim 3-6 \mathrm{~km}$ AGL) in the High-CCN simulations, there is a consistent $2-5-\mathrm{km}$-deep layer of weaker $B_{\mathrm{TH}}$ near and above the $0^{\circ} \mathrm{C}$ level in the High-CCN simulations, associated with weaker condensation rates and latent heat release evident in domain-mean profiles of these process rates. In other words, the convective updrafts in the High-CCN simulations are colder than those in the Low-CCN simulations with respect to the environments near and above the freezing level. The altitude and magnitude of this signal reversal also corresponds to the waning of the differences in the mean updrafts between the High-CCN and Low-CCN simulations (Fig. 8). At higher altitudes $(\sim 7-14 \mathrm{~km}$ AGL), there is a mixed response among the models, with most models showing alternating patches of stronger and weaker thermal buoyancy with increasing height through the deep convective updrafts. The three models with consistently stronger mean vertical velocities in the High-CCN simulations above $\sim 8 \mathrm{~km}$ AGL (UM, NU-WRF, WRF-Morr; Fig. 8) do not all have stronger thermal buoyancy in this region, which suggests that additional processes and terms are impacting the trends in the vertical velocities in these upper levels.

\section{b. Water vapor buoyancy ( $\left.B_{\mathrm{WV}}\right)$}

Because water vapor is lighter than dry air, regions of air with greater amounts of water vapor compared to the base state are more buoyant and lead to positive vertical accelerations. The $B_{\mathrm{Wv}}$ term is positive throughout the updrafts, meaning that these deep convective updrafts have greater water vapor amounts as compared to the base state, with the most intense values in the lower and middle troposphere (Figs. 12a-n). The magnitude of this term and its difference between the High-CCN and Low-CCN simulations is significantly lower (order of magnitude) than the thermal buoyancy term, and thus the $B_{\mathrm{WV}}$ term plays a lesser role in explaining the trends in updraft magnitudes. The $B_{\mathrm{WV}}$ term does, however, assist in explaining the physical processes associated with the thermal buoyancy term. In Figs. 12o-u, there are layers of weaker $B_{\mathrm{Wv}}$ in the High-CCN simulations (i.e., drier updrafts in the High-CCN simulations), which begin anywhere between 2 and $5 \mathrm{~km}$ AGL, depending on the model, and which extend upward. These regions of weaker 

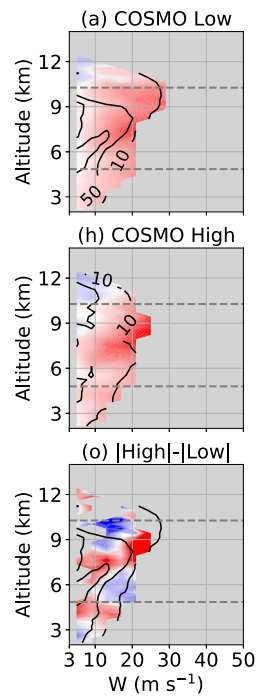

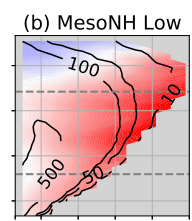

(i) MesoNH High

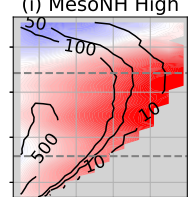

(p) |High|-|Low|

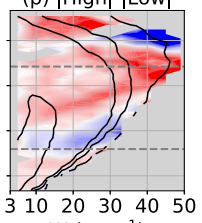

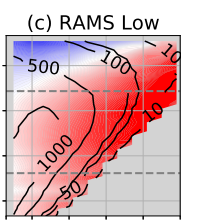

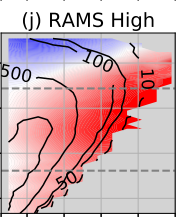

(q) |High|-|Low|

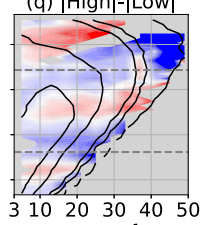

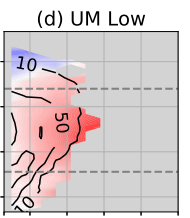

(k) UM High

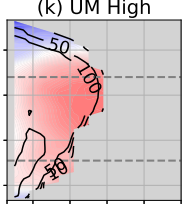

(r) |High|-|Low|

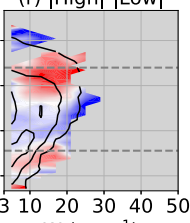

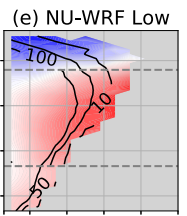

(I) NU-WRF High
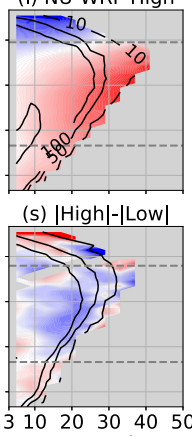

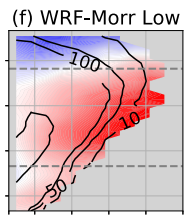

(m) WRF-Morr High
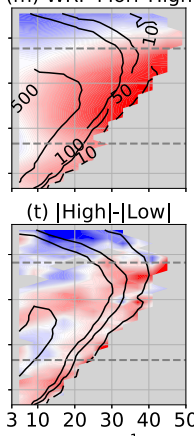

$\mathrm{W}\left(\mathrm{m} \mathrm{s}^{-1}\right)$

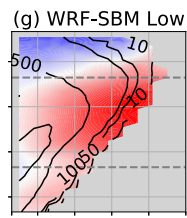

(n) WRF-SBM High
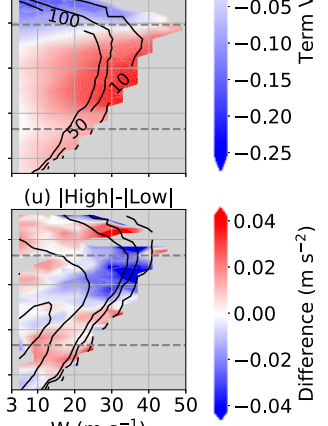

$\mathrm{W}\left(\mathrm{m} \mathrm{s}^{-1}\right)$

FIG. 11. Average thermal buoyancy $\left(B_{\mathrm{TH}}\right)$ term for the $(\mathrm{a})-(\mathrm{g})$ Low-CCN simulations and (h)-(n) High-CCN simulations. Values averaged over deep convective updrafts, as defined in the text, and subset by altitude and $w$ using $4 \mathrm{~m} \mathrm{~s}^{-1}$ increments. Black contours represent the number of grid points used for the Low-CCN and High-CCN simulations, respectively. (o)-(u) The difference in the absolute values between the High-CCN and Low-CCN results. The black contours in (o)-(u) represent the values from the Low-CCN simulations. The dashed gray lines represent the altitudes where the mean temperatures are $0^{\circ}$ and $-38^{\circ} \mathrm{C}$. Note that in (o)-(u), data are only shown for regions where data were present and had the same sign in both the Low-CCN and High-CCN simulations, where such comparisons are sensible.

$B_{\mathrm{WV}}$ in the High-CCN simulations generally overlap and are slightly offset to lower altitudes when compared to the regions of weaker thermal buoyancy (Figs. 11o-u). Because this analysis is focused on deep convective updrafts, these processes at lower altitudes are precursors to processes at their adjacent higher altitudes. In the High-CCN simulations, enhanced condensation that is associated with stronger updrafts and larger positive thermal buoyancy in the first few kilometers above cloud base ( $\sim 2-5 \mathrm{~km}$ AGL; Figs. 11o-u) robs the updraft of its water vapor and results in updrafts in the altitudes above this level (Figs. 12o-u). Therefore, near and above the $0^{\circ} \mathrm{C}$ level ( $\sim 4-8 \mathrm{~km}$ AGL), the High-CCN simulations have lower water vapor amounts, and thus weaker condensation rates and weaker thermal buoyancy than the Low-CCN simulations at these altitudes. While this relationship between water vapor and thermal buoyancy appears to be the dominant process in describing the trends in thermal buoyancy accelerations and the associated mean updraft trends below $\sim 8 \mathrm{~km}$ AGL, we
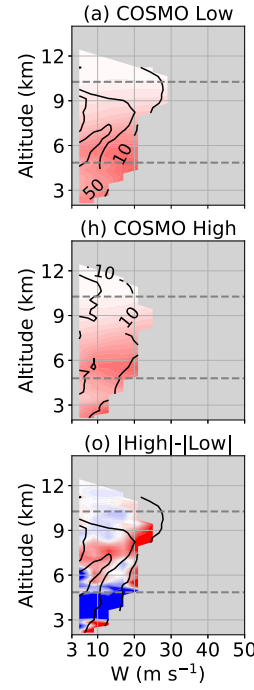
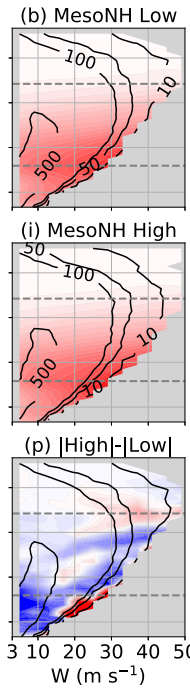
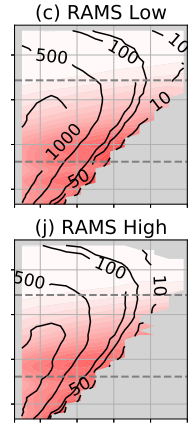

(q) |Highl- Low|

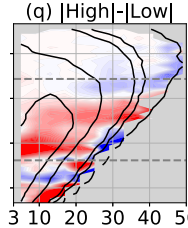

$\mathrm{W}\left(\mathrm{m} \mathrm{s}^{-1}\right)$

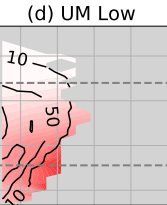

(k) UM High
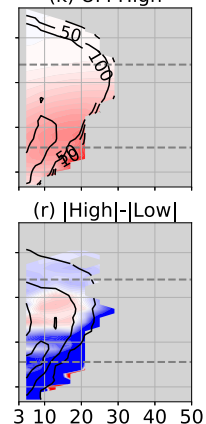

$\mathrm{W}\left(\mathrm{m} \mathrm{s}^{-1}\right)$

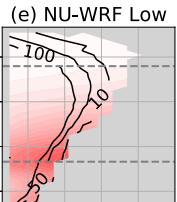

(I) NU-WRF High
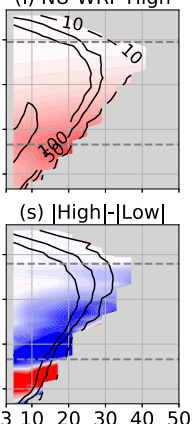

$\mathrm{W}\left(\mathrm{m} \mathrm{s}^{-1}\right)$

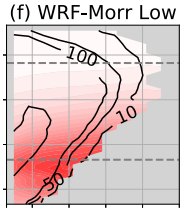

(m) WRF-Morr High
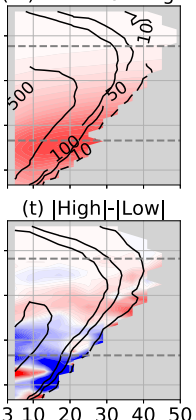

$\mathrm{W}\left(\mathrm{m} \mathrm{s}^{-1}\right)$
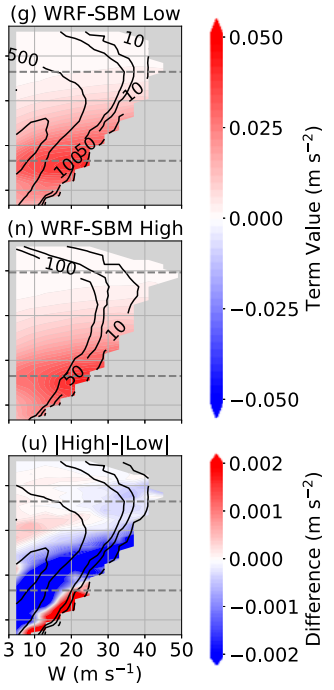

FIG. 12. As in Fig. 11, but for moisture buoyancy $\left(B_{\mathrm{WV}}\right)$. Note the change in color-bar scale from Fig. 11. 

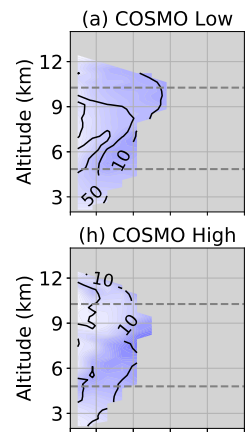

(o) |High|-|Low|

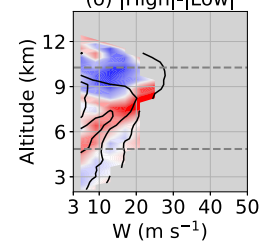

$\mathrm{W}\left(\mathrm{m} \mathrm{s}^{-1}\right)$

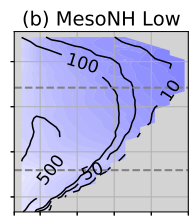

(i) MesoNH High
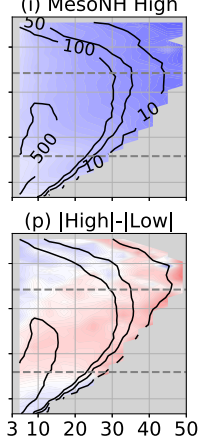

$\mathrm{W}\left(\mathrm{m} \mathrm{s}^{-1}\right)$
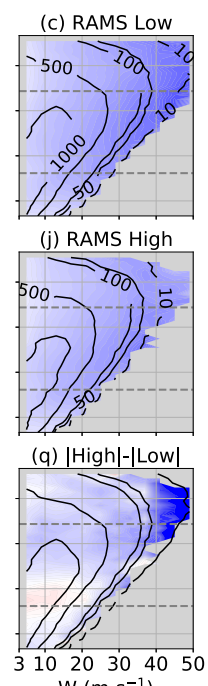

$\mathrm{W}\left(\mathrm{m} \mathrm{s}^{-1}\right)$

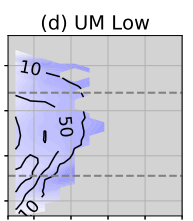

(k) UM High

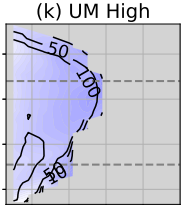

(r) |High|-|Low|

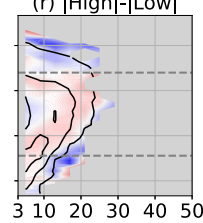

$\mathrm{W}\left(\mathrm{m} \mathrm{s}^{-1}\right)$

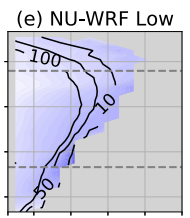

(I) NU-WRF High
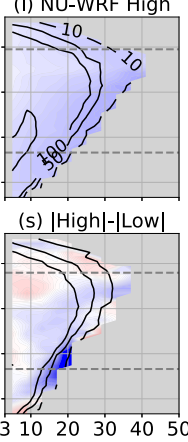

$\mathrm{W}\left(\mathrm{m} \mathrm{s}^{-1}\right)$

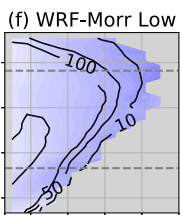

(m) WRF-Morr High
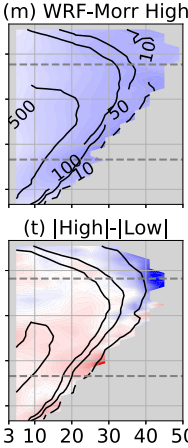

$\mathrm{W}\left(\mathrm{m} \mathrm{s}^{-1}\right)$

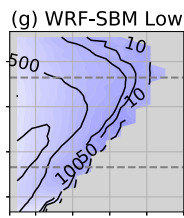

(n) WRF-SBM High
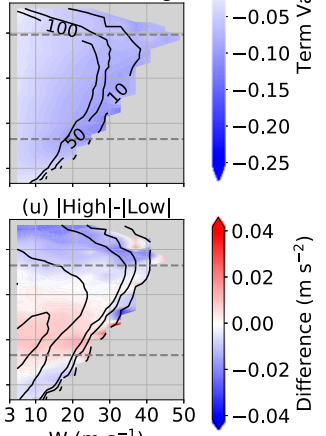

$\mathrm{W}\left(\mathrm{m} \mathrm{s}^{-1}\right)$

FIG. 13. As in Fig. 11, but for condensate loading $\left(B_{\mathrm{CL}}\right)$.

cannot rule out the impacts of entrainment on altering the water vapor and thermal buoyancy in these simulations.

\section{c. Condensate loading buoyancy $\left(B_{\mathrm{CL}}\right)$}

Opposing the positive thermal and moisture buoyancy terms within the updraft, the buoyancy accelerations due to condensate loading $\left(B_{\mathrm{CL}}\right)$ are negative throughout the updraft (Figs. 13a-n). Below the $0^{\circ} \mathrm{C}$ level, most models (COSMO, MesoNH, RAMS, NU-WRF, and WRF-SBM) depict weaker condensate loading in the High-CCN simulation, meaning that there is less condensate in the High-CCN updrafts at these levels. This difference between the High-CCN and Low-CCN simulations also contributes to the stronger vertical velocities in the High-CCN simulations at these lower altitudes (Fig. 8). This signal is a result of reduced amounts of liquid water mass (primarily rain) in these lower updraft levels, as more numerous, smaller cloud droplets are lofted within the updraft in the High-CCN simulations. As such, above the $0^{\circ} \mathrm{C}$ level $(\sim 5 \mathrm{~km}$ AGL), all models initially show an increase in condensate loading in the High-CCN simulations, which also contributes to the waning responses in the mean vertical velocities.

Despite these relatively consistent signals in condensate loading among the models, the condensate loading generally plays a lesser role than the thermal buoyancy in explaining the differences between the High-CCN and Low-CCN simulations in all the models except COSMO, which can be seen by comparing the magnitudes of the differences between the High$\mathrm{CCN}$ and Low-CCN simulations (Figs. 10o-u and $12 \mathrm{o}-\mathrm{u}$ ). The magnitude of the condensate loading term was between $20 \%$ and $75 \%$ (median calculated from fixed model levels between 2 and $14 \mathrm{~km} \mathrm{AGL}$ ) of the magnitude of the thermal buoyancy term for all the models except COSMO, when comparing the difference in the mean profiles for the High-CCN and Low$\mathrm{CCN}$ cases (comparing light green and dark green lines in Fig. 15). Therefore, in these simulations, the thermal buoyancy is more important than the condensate loading in explaining the changes in the deep convective updraft $w$ between the
High-CCN and Low-CCN simulations. There are a few exceptions, however, such as the middle tropospheric levels, where the thermal buoyancy response wanes. It is also important to note the condensate loading can impact downdrafts and cold pools, which can initiate new convection and affect updraft magnitudes.

We compared this result of the more impactful role of thermal buoyancy as compared to condensate loading in deep convective updrafts to several recent studies that have also explicitly assessed the buoyancy terms of the $w$ tendency equation. The ACPC MIP results are similar to those of continental deep convection case studies for a midlatitude squall line and an isolated, tropical cloud [Tao and Li (2016) and Fan et al. (2018), respectively]. However, these results appear to differ from Storer and van den Heever (2013), which showed that changes in condensate loading under varying $\mathrm{CCN}$ concentrations were larger than changes in latent heating in their idealized simulations of oceanic, tropical convection. This comparison between these studies provides further evidence that aerosol effects on updrafts are dependent on environmental conditions.

\section{d. $V P P G$}

The VPPG term is generally weakly positive below $\sim 6 \mathrm{~km}$ AGL and more strongly negative above $\sim 6 \mathrm{~km}$ AGL (Figs. 14a-n). Importantly, it is of similar magnitude to the $B_{\mathrm{TH}}$ and $B_{\mathrm{CL}}$ terms. This term has both buoyant and dynamic components (e.g., Klemp 1987). In these simulations, this term often acts to oppose the net buoyancy, which demonstrates a significant contribution from the buoyant component to the total VPPG term. As such, in many locations throughout the profiles, the VPPG differences between the High-CCN and Low-CCN simulations (Figs. 14o-u) offset the differences between the High-CCN and Low-CCN buoyancy terms. For example, the differences in the VPPG terms create weaker vertical accelerations in the High- $\mathrm{CCN}$ simulations from $\sim 3-5 \mathrm{~km}$ AGL, where the buoyancy terms create stronger vertical accelerations in the High-CCN simulations. 

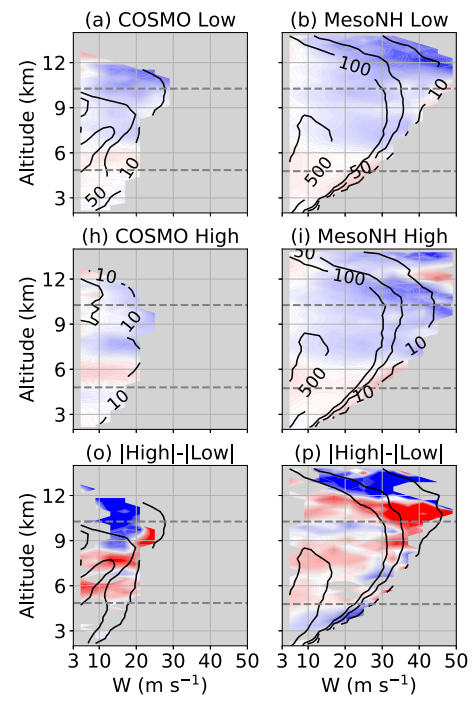

$\mathrm{W}\left(\mathrm{m} \mathrm{s}^{-1}\right)$
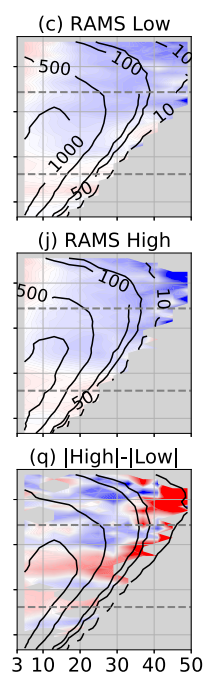

$\mathrm{W}\left(\mathrm{m} \mathrm{s}^{-1}\right)$

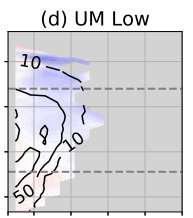

(k) UM High

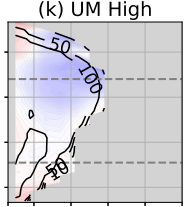

(r) |High|-|Low|

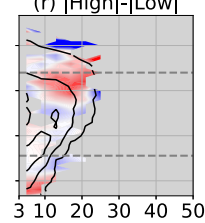

$\mathrm{W}\left(\mathrm{m} \mathrm{s}^{-1}\right)$

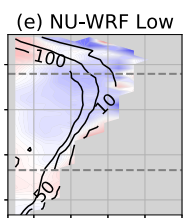

(I) NU-WRF High
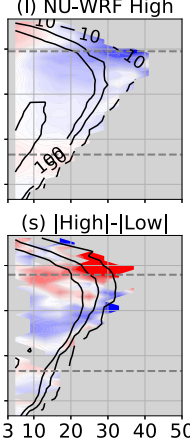

$\mathrm{W}\left(\mathrm{m} \mathrm{s}^{-1}\right)$

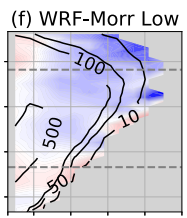

(m) WRF-Morr High
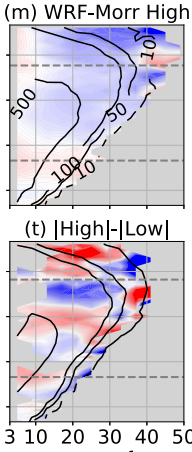

$\mathrm{W}\left(\mathrm{m} \mathrm{s}^{-1}\right)$

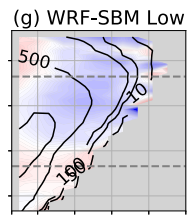

(n) WRF-SBM High
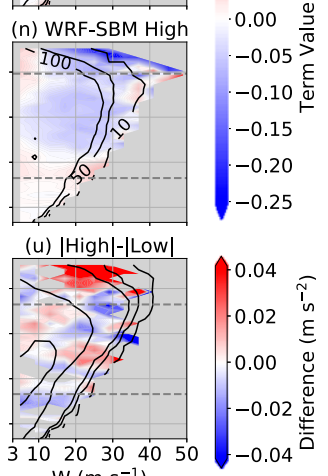

$\mathrm{W}\left(\mathrm{m} \mathrm{s}^{-1}\right)$

FIG. 14. As in Fig. 11, but for the vertical perturbation pressure gradient (VPPG).

In Fig. 15 (left column), the sum of the buoyancy accelerations $\left(B_{\text {sum }}\right)$, the sum of the buoyancy and VPPG accelerations $\left(B_{\text {sum }}+\right.$ VPPG $)$, and the vertical velocities are presented, averaged over the deep convective updrafts, and shown as a difference (High-CCN - Low-CCN). Generally, when the acceleration differences are negative (positive), the mean updraft response begins to decrease (increase) at or slightly above that altitude. In some models at certain altitudes, the $B_{\text {sum }}+$ VPPG term is similar to the $B_{\text {sum, }}$, suggesting only a small impact from the VPPG term in driving the mean updraft changes between the High-CCN and Low-CCN simulations. However, the VPPG plays a significant role throughout the updraft depth in most of the models, particularly in the mid- and uppertropospheric levels (Fig. 15). At these altitudes and in most of the models (COSMO, RAMS, UM, NU-WRF, WRF-Morr), the positive (negative) differences in $B_{\text {sum }}+$ VPPG accelerations are more positively correlated with the increases (decreases) in the vertical derivatives of w, as compared to $B_{\text {sum }}$ alone. Therefore, the combination of the buoyancy and VPPG terms better explains the mean updraft responses at these altitudes. These results demonstrate that the VPPG term can be important in terms of affecting the mean updraft response to varying $\mathrm{CCN}$ concentrations and are consistent with recent studies (Tao and Li 2016; Chen et al. 2020).

\section{e. Advection terms}

For completeness, the analyses are shown for accelerations due to HADV and VADV in Figs. 16 and 17, respectively. The horizontal advection term (Fig. 16) has weakly negative accelerations below, more strongly positive accelerations above $\sim 10 \mathrm{~km}$ AGL, and is generally weaker than most of the other terms. This is due to the counteraction of both positive and negative HADV accelerations, which are caused by the opposite gradients in $w$ on the upwind and downwind sides of the updrafts, respectively. Therefore, while locally this term can play a very significant role within individual updrafts (see Fig. 10) when assessing the mean updraft response, this HADV term has a limited impact, except for the extreme upper levels (e.g., above $11 \mathrm{~km} \mathrm{AGL)} \mathrm{of} \mathrm{the} \mathrm{updrafts.}$

In the mean updrafts, the accelerations associated with vertical advection (Fig. 17) are much stronger than the accelerations associated with horizontal advection. The vertical advection term is negative below and positive above the altitude of the maximum updraft, where $\partial w / \partial z$ is positive and negative, respectively, in both the High- and Low-CCN cases. This term neutralizes the sum of the buoyancy and VPPG terms, which is due to the fact that the full life cycle of updrafts is being assessed in this study, which captures both decaying and intensifying stages. Therefore, in the mean, $\partial w / \partial t$ will be close to zero, and thus, the VADV term will act to balance the sum of the other terms. While these advection terms are locally strong and are essential for closing the $w$ tendency equation, their interpretations in this analysis framework are somewhat extraneous.

\section{Conclusions and discussion}

As part of the ACPC initiative, a MIP was organized and completed in order to assess the consistency of CCN impacts on deep convective clouds among seven state-of-the-art cloudresolving models. The ACPC MIP represents the first time that an international, coordinated intercomparison study has been used to determine the robustness of simulated aerosol impacts on a field of deep convective clouds. Seven models were used to simulate the same case study of a scattered deep convective cloud field near Houston, Texas, with both relatively high and low initial CCN concentrations.

Despite efforts to keep the initialization data and model setup as consistent as possible, there is still a large spread in the simulated convection, which is likely due to the different parameterizations and dynamical cores within the models, which alter how the simulations evolve. That said, all of the models produce scattered deep convective clouds around Houston during the 12-h period when convective clouds are observed 

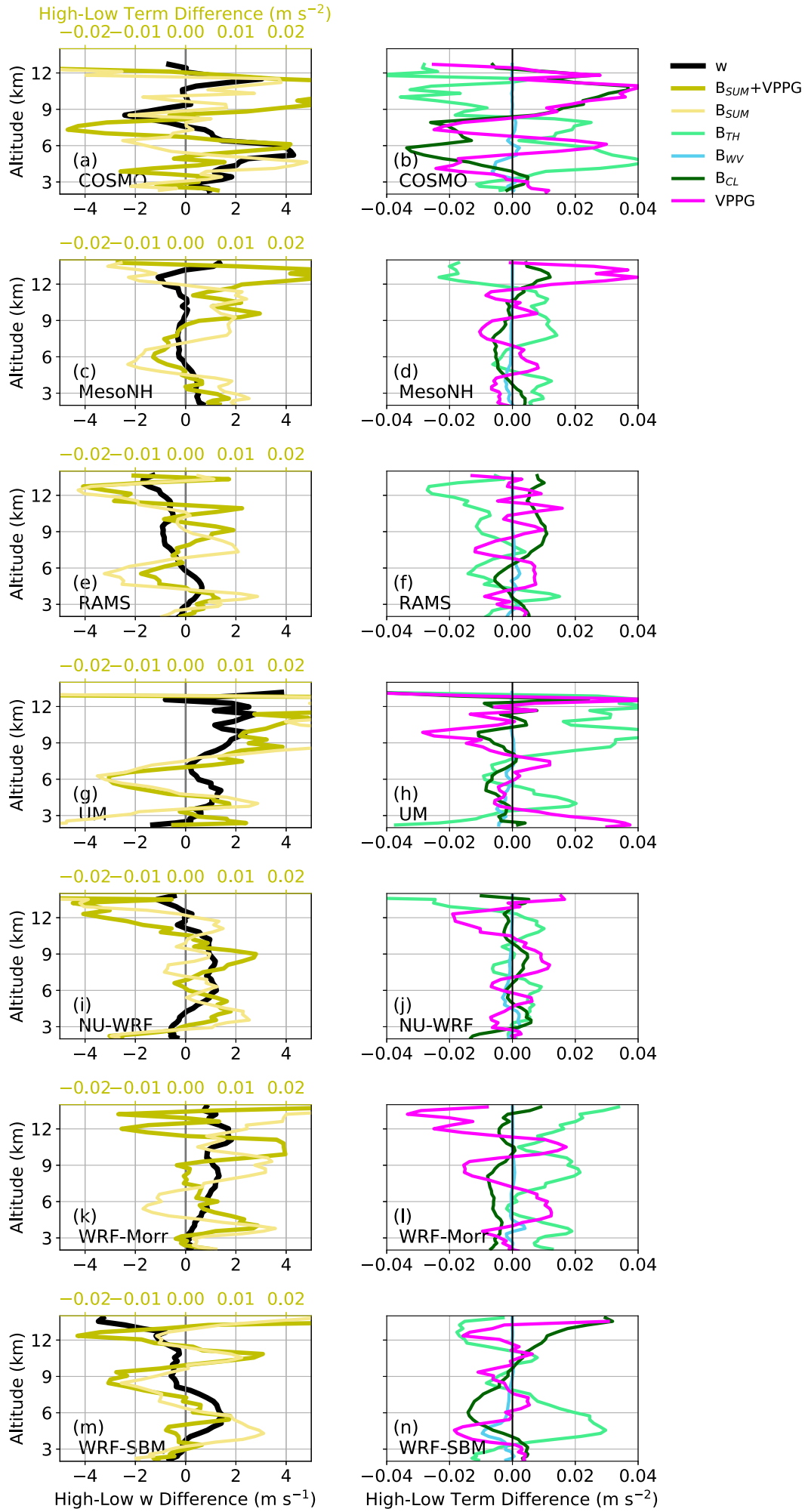

FIG. 15. (left) Differences (High-CCN minus Low-CCN) in the mean profiles of vertical velocities (black), $B_{\text {SUM }}$ accelerations (light yellow), and $B_{\text {SUM }}+$ VPPG accelerations (dark yellow) within the deep convective updrafts for the seven models. (right) Differences (High-CCN minus Low-CCN) in mean profiles of $B_{\mathrm{TH}}$, (light green), $B_{\mathrm{WV}}$ (light blue), $B_{\mathrm{CL}}$ (dark green), and VPPG (purple) accelerations within the deep convective updrafts for the seven models. 

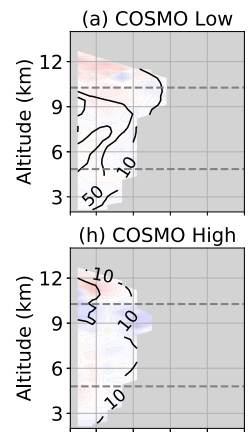

(o) |High|-|Low|

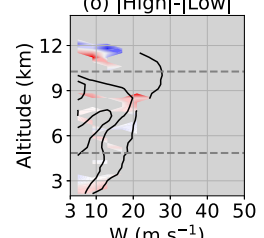
$\mathrm{W}\left(\mathrm{m} \mathrm{s}^{-1}\right)$

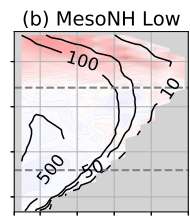

(i) MesoNH High

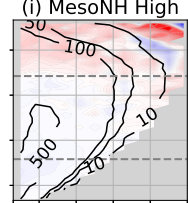

(p) |High|-|Low|

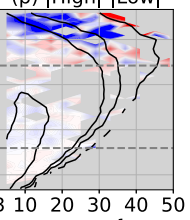

$\mathrm{W}\left(\mathrm{m} \mathrm{s}^{-1}\right)$
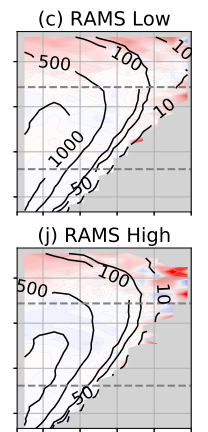

(q) |High|-|Low|

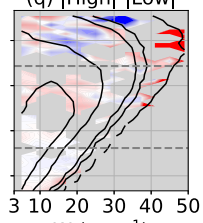

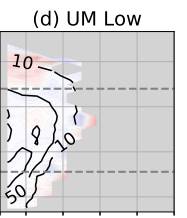

(k) UM High

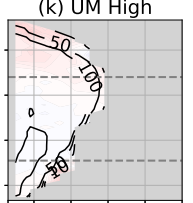

(r) |High|-|Low|

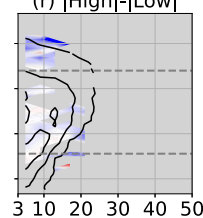

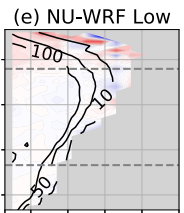

(I) NU-WRF High
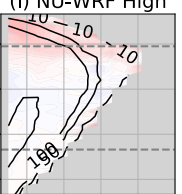

(s) |High|-|Low|

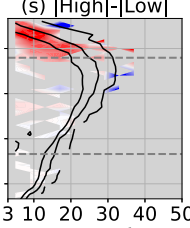

$\mathrm{W}\left(\mathrm{m} \mathrm{s}^{-1}\right)$

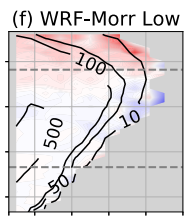

(m) WRF-Morr High
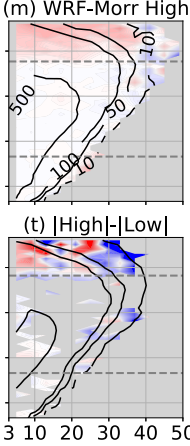

$\mathrm{W}\left(\mathrm{m} \mathrm{s}^{-1}\right)$

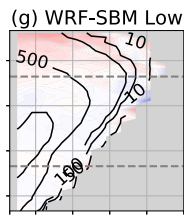

(n) WRF-SBM High
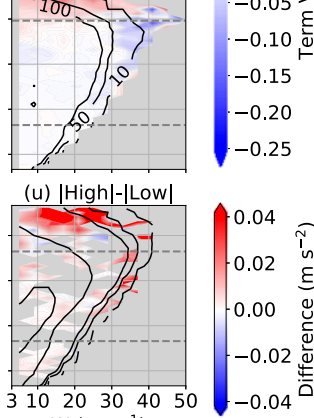

$\mathrm{W}\left(\mathrm{m} \mathrm{s}^{-1}\right)$

FIG. 16. As in Fig. 11, but for the accelerations due to horizontal advection (HADV).

for this case. The modeled deep convective cloud updrafts are identified and compared between the High-CCN and Low-CCN simulations in order to determine the range of model responses in updraft frequency and intensity due to varying $\mathrm{CCN}$ concentrations. The terms of the vertical velocity tendency equation are also calculated and compared between the High-CCN and Low-CCN simulations in order to determine the physical processes that were associated with the $\mathrm{CCN}$-induced updraft responses.

There are several consistent trends among the majority of models:

- In general, the net change to the mean deep convective updraft magnitudes are between $-5 \%$ and $+15 \%$ at most altitudes over the 12-h simulated cloud field.

- All of the models produce stronger updrafts $(+5 \%$ to $+15 \%$ ) from $\sim 4$ to $7 \mathrm{~km}$ AGL in the High-CCN simulations, which is associated with enhanced condensational latent heating, despite the fact that the majority of the models utilize saturation adjustment schemes. This consistent $\mathrm{CCN}$-induced response is likely related to an environmental feedback process in all the models, whereby the High-CCN simulations have increased environmental instability as a result of warmer boundary layer $(\sim 0-3 \mathrm{~km}$ AGL) temperatures and cooler cloud level ( $\sim 3-6 \mathrm{~km}$ AGL) temperatures in the clouds' environment.

- The consistent updraft response from $\sim 4$ to $7 \mathrm{~km}$ AGL was in keeping with a shift in the normalized distribution of deep convective vertical velocities at these altitudes toward relatively more frequent stronger vertical velocities and less frequent weaker vertical velocities in the High-CCN simulations.

- From $\sim 5$ to $8 \mathrm{~km} \mathrm{AGL}$, the mean updraft differences between the High-CCN and Low-CCN simulations wanes in most models. This is associated with the drying of the updrafts in the High-CCN simulations, which results from the enhanced condensation and subsequent water vapor loss at the altitudes below, thereby limiting the amount of water vapor transported upward to these regions.

- The condensate loading term has similar trends in most models, with decreased condensate loading below and enhanced condensate loading above the freezing level in the High-CCN simulations. However, most of the models reveal that differences in condensate loading accelerations between the High-CCN and Low-CCN simulations were generally smaller in magnitude than the differences in thermal buoyancy accelerations, and therefore, less impactful on the mean updraft responses to varying $\mathrm{CCN}$ concentrations.

The many consistent trends found in this study are perhaps surprising given the range of models and parameterizations utilized in this study. The ACPC MIP's parameterization space includes differences in the hydrometeor distribution parameterizations (i.e., $2 \mathrm{M}$ vs spectral bin), differences in saturation adjustment schemes (i.e., saturation adjustment vs prognosed or diagnosed supersaturation), and differences in parameterized aerosol processes (i.e., fixed vs evolving aerosol profiles). The consistent response may be a consequence of moderating feedback processes and/or the fact that these analyses depict a field of scattered deep convective clouds throughout a 12-h period, as opposed to one, isolated cloud.

However, there were also some inconsistent results in the updraft response to varying the $\mathrm{CCN}$ concentrations among the models:

- Some models produce significantly more and/or larger deep, convective updrafts in the High-CCN simulations, while other models produce fewer and/or smaller updrafts, which may be related to the differences in the evolution of the environmental conditions within the models.

- Above $\sim 8 \mathrm{~km}$ AGL, the mean updraft response to aerosol loading is mixed with some models having neutral to slightly weaker updrafts (generally, $-5 \%$ to $0 \%$ ) in the High-CCN simulations, and the others showing slightly stronger $(\sim+10 \%)$ 

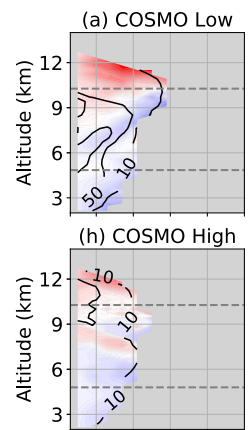

(o) |High|-|Low|

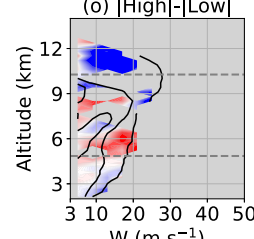

$\mathrm{W}\left(\mathrm{m} \mathrm{s}^{-1}\right)$

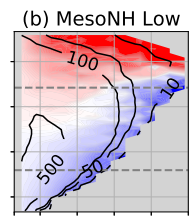

(i) MesoNH High
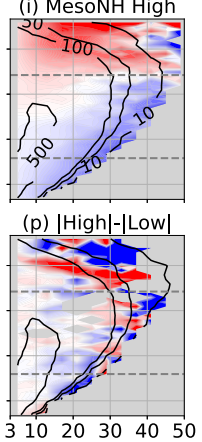

$\mathrm{W}\left(\mathrm{m} \mathrm{s}^{-1}\right)$
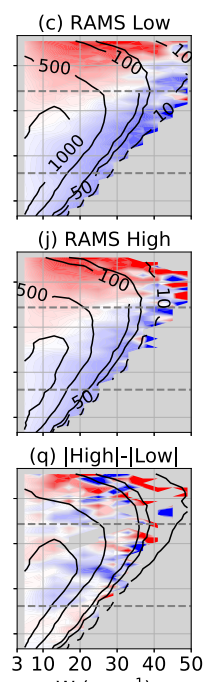

$\mathrm{W}\left(\mathrm{m} \mathrm{s}^{-1}\right)$

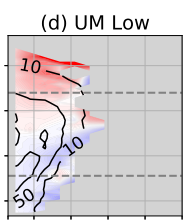

(k) UM High

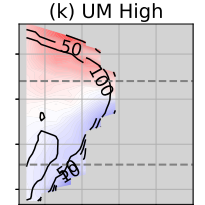

(r) $|\mathrm{High}|-\mid$ Low $\mid$

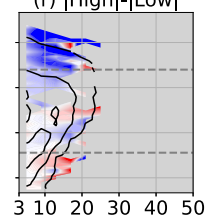

$\mathrm{W}\left(\mathrm{m} \mathrm{s}^{-1}\right)$

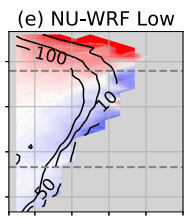

(I) NU-WRF High
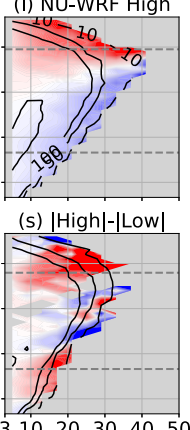

$\mathrm{W}\left(\mathrm{m} \mathrm{s}^{-1}\right)$

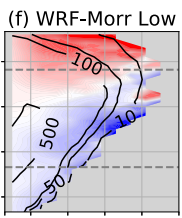

(m) WRF-Morr High

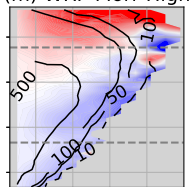

(t) |High/-|Low|

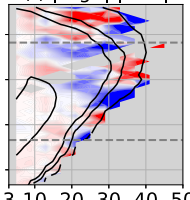

10203040
$W\left(\mathrm{~m} \mathrm{~s}^{-1}\right)$

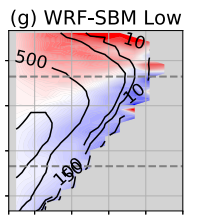

(n) WRF-SBM High
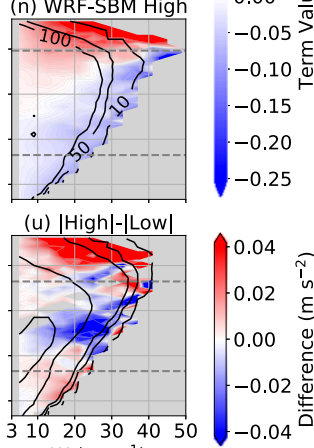

$\mathrm{W}\left(\mathrm{m} \mathrm{s}^{-1}\right)$

FIG. 17. As in Fig. 11, but for accelerations due to vertical advection (VADV).

updrafts. While the thermal buoyancy plays a significant role at these altitudes, this updraft response above $\sim 8 \mathrm{~km}$ AGL is better correlated with the combination of the thermal buoyancy, condensate loading buoyancy, and the vertical perturbation pressure gradient (VPPG) terms than the buoyancy terms alone, demonstrating the potential importance of the VPPG term in aerosol-impact studies.

While this study focused on updraft intensity and frequency, additional research focusing on other cloud properties and processes (e.g., precipitation, downdrafts, hydrometeor amounts and types) within this ACPC MIP are being undertaken. Furthermore, many studies have shown that the most significant and consistent $\mathrm{CCN}$ effects are at the initial stages of cloud development and that feedbacks to cold pools, convective anvils and the environment may modulate $\mathrm{CCN}$ effects at later times in a cloud's life cycle (e.g., van den Heever et al. 2006; Tao et al. 2007), which were not assessed in the composite analyses presented here, which encompassed many convective clouds over a 12 -h period. To assess the consistency of the aerosol impacts on cloud evolution and life cycles in these ACPC MIP data, individual clouds should be identified and tracked. Recent software [Tracking and Object-Based Analysis of Clouds (tobac)] has been developed for this purpose and tested with some of the ACPC MIP simulation data (Heikenfeld et al. 2019). Through tracking individual clouds in this dataset, the robustness of aerosol impacts on the evolution of clouds for the ACPC MIP could be assessed.

In this study, each model was allowed to freely evolve through its model integration. While this better represents reality and demonstrates the range of responses produced from current state-of-the-art models, methods that either fully constrain the dynamics (e.g., Grabowski 2015; Hill et al. 2015) or utilize the same dynamical core (e.g., Fan et al. 2017) would help address the question as to which processes in the various model parameterizations are causing differences in the model responses. While this has been studied with a few model microphysical parameterizations, a more comprehensive model intercomparison study under such a framework would also be a useful endeavor.

While research focused on model comparisons is useful in determining the consistency of model responses, comprehensive observations of cloud microphysical processes in deep convective clouds are needed to confirm the correct model representations of fundamental microphysical processes and to validate and/or constrain the complex mechanisms, parameters and responses proposed in modeling studies, such as through the use of polarimetric radar (e.g., Fridlind et al. 2019; Matsui et al. 2020b). For example, the current understanding of ice formation pathways in deep convective systems (e.g., Morrison et al. 2020; Korolev et al. 2020) remain uncertain, and the uncertainties in these processes and how they are parameterized need to be considered when interpreting model-based results. While careful comparisons with microphysical observations alleviate some uncertainties (e.g., Fridlind et al. 2017), a combination of consistent laboratory experiments, realworld observations, and model development and research will be needed to overcome these issues. As such, the ACPC MIP assisted in motivating the Tracking Aerosol Convection Interactions Experiment (TRACER; Jensen 2019), which will take place in Houston in 2021-22. The observational data from this field campaign, both within clouds and their environments, will be very useful in assessing the mechanisms proposed in this study and addressing some of the continued observational needs in cloud microphysics.

Acknowledgments. The reviews and suggestions from Dr. Wei-Kuo Tao and two anonymous reviewers improved the clarity of this manuscript and are greatly appreciated. This work was organized through the Aerosol-CloudPrecipitation-Climate working group, which was developed 


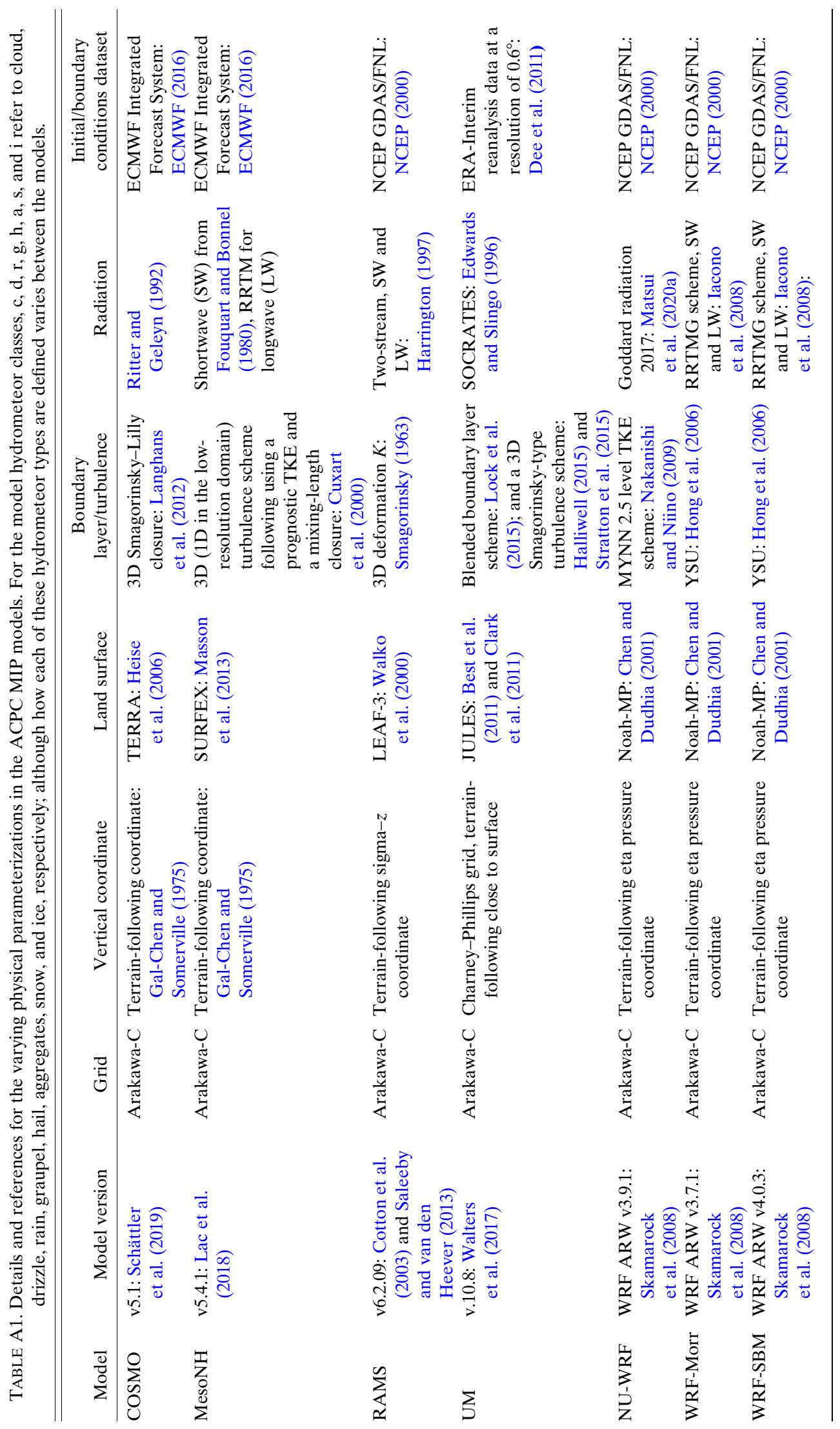




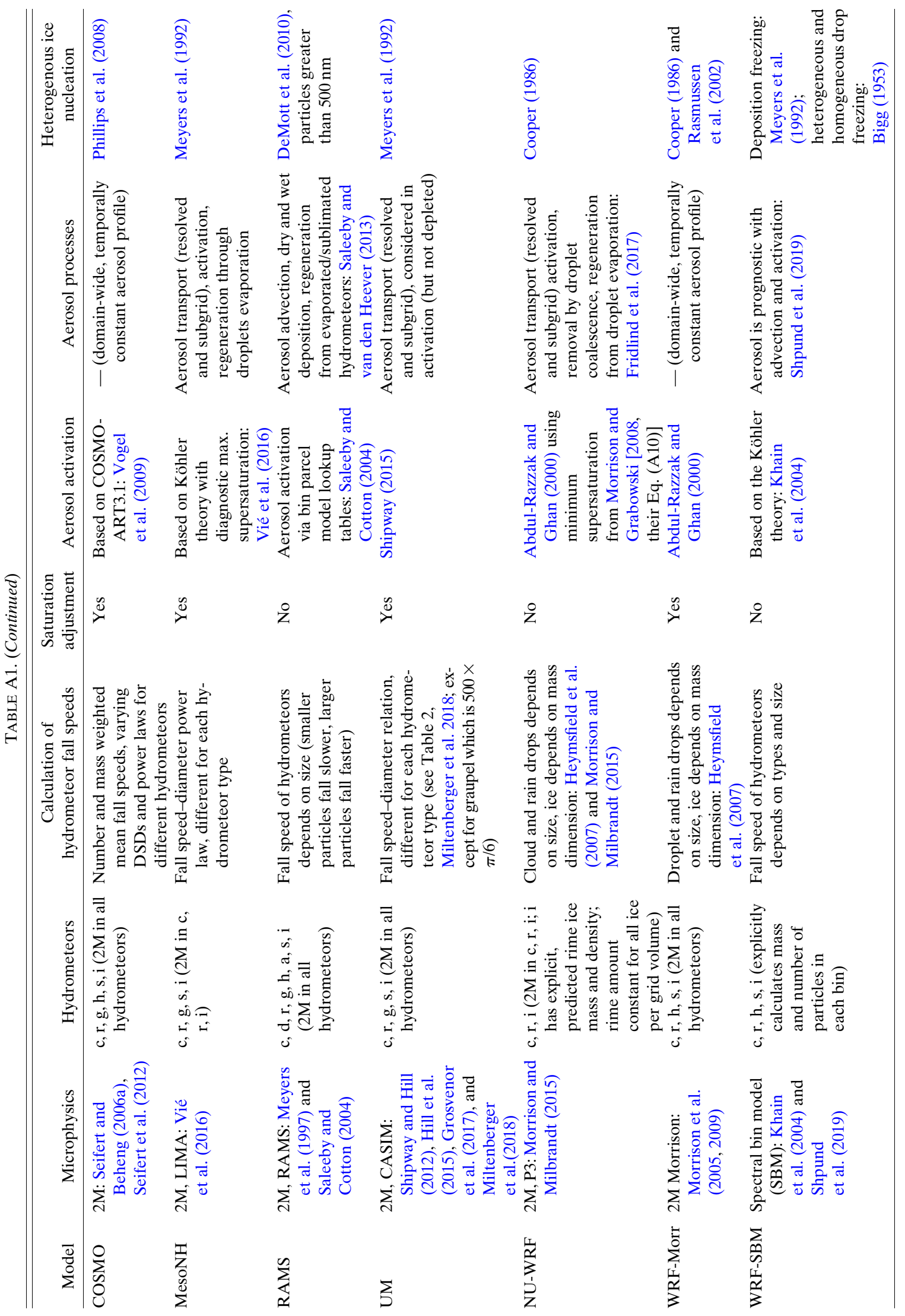


through the cooperation of the Integrated Land EcosystemAtmosphere Processes Study, International Global Atmospheric Chemistry and Global Energy and Water Cycle Experiment. We would like to acknowledge Johannes Quaas and Daniel Rosenfeld for leading ACPC during the time of this work, as well as Meinrat Andreae for assisting with the data used for the aerosol initialization. We would also like to acknowledge the U.K. CEDA JASMIN which provided the data storage and computational resources for these simulations and their analysis. PJM and SCV were supported by NASA Grant 80NSSC18K0149. The RAMS simulations were conducted on the NSF Cheyenne supercomputer, supported by the NSF Graduate Research Fellowship Program (NSF Grant DGE-1840343). PS and MH acknowledge support from the European 330 Union's Seventh Framework Programme (FP7/2007-2013)/ERC Grant Agreement FP7-280025 (ACCLAIM), from the European Union's Seventh Framework Programme (FP7/2007-2013) Project BACCHUS under Grant Agreement 603445, and as well as by the European Research Council (ERC) project (RECAP) under the European Union's Horizon 2020 research and innovation program with Grant Agreement 724602. For the UM simulations, AKM acknowledges use of the Monsoon2 system, a collaborative facility supplied under the Joint Weather and Climate Research Programme, a strategic partnership between the Met Office and the Natural Environment Research Council. AMF and TM were supported by the Office of Science (BER), U.S. Department of Energy, under Agreements DE-SC0006988 and DE-SC0016237, and by the NASA Modeling, Analysis and Prediction program, and resources supporting their work were provided by the NASA High-End Computing Program through the NASA Advanced Supercomputing Division at NASA Ames. The COSMO simulations at KIT were performed on the supercomputer ForHLR funded by the Ministry of Science, Research and the Arts Baden-Württemberg and by the Federal Ministry of Education and Research.

Data availability statement. All simulation data are stored and can be accessed on the U.K. CEDA JASMIN supercomputer.

\section{APPENDIX A}

\section{Parameterizations in the ACPC MIP Models}

We present the details and the associated references for the models that participated in the ACPC MIP and the parameterizations that they used for these simulations in Table A1.

\section{APPENDIX B}

\section{Calculation of Tendency Equation Terms and Model Base States}

The terms of Eq. (1) are calculated from each model's output on their native grids and at the center of each model grid box. In some instances, variables are interpolated by one-half of the model grid spacing in either the $x, y$, or $z$ direction in order to calculate each term's value at the center of the grid box. Similarly, $w$, which is prognosed at the top and bottom faces of a model grid box, is interpolated to the center of each model grid box, such that the analyses presented in this study all occur at the center of each model grid box.

Because all the models calculate their base states differently, we make the same approximation for the base state for each model's data to allow for more comparable results. This base state is calculated as follows. At each model output time, all noncloudy model grid points (total condensate $<0.1 \mathrm{~g} \mathrm{~kg}^{-1}$ ) and their respective model altitudes are collected. These data are used to create one base-state profile with $20 \mathrm{~m}$ vertical grid spacing, whereby the base-state value is the median of all data within $10 \mathrm{~m}$ in the vertical from the grid center. This profile is then smoothed with a $1 \mathrm{~km}$ triangle function. This base-state profile is calculated for each time and is then linearly interpolated to each model grid point's altitude for calculating the vertical tendency equation terms.

\section{REFERENCES}

Abdul-Razzak, H., and S. J. Ghan, 2000: A parameterization of aerosol activation: 2. Multiple aerosol types. J. Geophys. Res., 105, 6837-6844, https://doi.org/10.1029/1999JD901161.

Albrecht, B. A., 1989: Aerosols, cloud microphysics, and fractional cloudiness. Science, 245, 1227-1230, https://doi.org/10.1126/ science.245.4923.1227.

Andreae, M. O., D. Rosenfeld, P. Artaxo, A. A. Costa, G. P. Frank, K. M. Longo, and M. A. F. Silva-Dias, 2004: Smoking rain clouds over the Amazon. Science, 303, 1337-1342, https:// doi.org/10.1126/science.1092779.

Barthlott, C., and C. Hoose, 2018: Aerosol effects on clouds and precipitation over central Europe in different weather regimes. J. Atmos. Sci., 75, 4247-4264, https://doi.org/10.1175/ JAS-D-18-0110.1.

Best, M. J., and Coauthors, 2011: The Joint UK Land Environment Simulator (JULES), model description-Part 1: Energy and water fluxes. Geosci. Model Dev., 4, 677-699, https://doi.org/ 10.5194/gmd-4-677-2011.

Bigg, E. K., 1953: The formation of atmospheric ice crystals by the freezing of droplets. Quart. J. Roy. Meteor. Soc., 79, 510-519, https://doi.org/10.1002/qj.49707934207.

Chen, F., and J. Dudhia, 2001: Coupling an advanced land surfacehydrology model with the Penn State-NCAR MM5 modeling system. Part I: Model implementation and sensitivity. Mon. Wea. Rev., 129, 569-585, https://doi.org/10.1175/1520-0493(2001) $129<0569$ :CAALSH $>2.0 . \mathrm{CO} ; 2$.

Chen, Q., J. Fan, Y. Yin, and B. Han, 2020: Aerosol impacts on mesoscale convective systems forming under different vertical wind shear conditions. J. Geophys. Res. Atmos., 125, e2018JD030027, https://doi.org/10.1029/2018JD030027.

Clark, D. B., and Coauthors, 2011: The Joint UK Land Environment Simulator (JULES), model description-Part 2: Carbon fluxes and vegetation dynamics. Geosci. Model Dev., 4, 701-722, https:// doi.org/10.5194/gmd-4-701-2011.

Cooper, W. A., 1986: Ice initiation in natural clouds. Meteor. Monogr., 43, 29-32, https://doi.org/10.1175/0065-9401-21.43.29.

Cotton, W. R., and Coauthors, 2003: RAMS 2001: Current status and future directions. Meteor. Atmos. Phys., 82, 5-29, https:// doi.org/10.1007/s00703-001-0584-9.

Cuxart, J., P. Bougeault, and J. L. Redelsperger, 2000: A turbulence scheme allowing for mesoscale and large-eddy simulations. Quart. J. Roy. Meteor. Soc., 126, 1-30, https://doi.org/10.1002/ qj.49712656202. 
Dee, D. P., and Coauthors, 2011: The ERA-Interim reanalysis: Configuration and performance of the data assimilation system. Quart. J. Roy. Meteor. Soc., 137, 553-597, https://doi.org/ 10.1002/qj.828.

DeMott, P. J., and Coauthors, 2010: Predicting global atmospheric ice nuclei distributions and their impacts on climate. Proc. Natl. Acad. Sci. USA, 107, 11217-11222, https://doi.org/ 10.1073/pnas.0910818107.

Du, J., 2011: GCIP/EOP surface: Precipitation NCEP/EMC 4KM gridded data (GRIB) stage IV data, version 1.0. UCAR/NCAR Earth Observing Laboratory, accessed 1 January 2017, https:// doi.org/10.5065/D6PG1QDD.

ECMWF, 2016: IFS documentation CY41R2: Parts III-VI. ECMWF Rep., 556 pp., http://www.ecmwf.int/en/forecasts/documentationand-support/changes-ecmwf-model/ifs-documentation.

Edwards, J. M., and A. Slingo, 1996: Studies with a flexible new radiation code. I: Choosing a configuration for a large-scale model. Quart. J. Roy. Meteor. Soc., 122, 689-719, https://doi.org/10.1002/ qj. 49712253107.

Fan, J., R. Zhang, G. Li, and W. K. Tao, 2007: Effects of aerosols and relative humidity on cumulus clouds. J. Geophys. Res., 112, D14204, https://doi.org/10.1029/2006JD008136.

_ - and Coauthors, 2009: Dominant role by vertical wind shear in regulating aerosol effects on deep convective clouds. J. Geophys. Res., 114, D22206, https://doi.org/10.1029/2009JD012352.

—, L. R. Leung, Z. Li, H. Morrison, H. Chen, Y. Zhou, Y. Qian, and Y. Wang, 2012: Aerosol impacts on clouds and precipitation in eastern China: Results from bin and bulk microphysics. J. Geophys. Res., 117, D00K36, https://doi.org/10.1029/ 2011JD016537.

— , and Coauthors, 2017: Cloud-resolving model intercomparison of an MC3E squall line case: Part I-Convective updrafts. J. Geophys. Res. Atmos., 122, 9351-9378, https://doi.org/ 10.1002/2017JD026622.

— , and Coauthors, 2018: Substantial convection and precipitation enhancements by ultrafine aerosol particles. Science, 359, 411-418, https://doi.org/10.1126/science.aan8461.

Fouquart, Y., and B. Bonnel, 1980: Computations of solar heating of the Earth's atmosphere-A new parameterization. Beitr. Phys. Atmos., 53, 35-62.

Fridlind, A. M., and Coauthors, 2004: Evidence for the predominance of mid-tropospheric aerosols as subtropical anvil cloud nuclei. Science, 304, 718-722, https://doi.org/10.1126/science.1094947.

— , and Coauthors, 2017: Derivation of aerosol profiles for MC3E convection studies and use in simulations of the 20 May squall line case. Atmos. Chem. Phys., 17, 5947-5972, https:// doi.org/10.5194/acp-17-5947-2017.

— ments to constrain simulated convective cell evolution: A pilot study with Lagrangian tracking. Atmos. Meas. Tech., 12, 29793000, https://doi.org/10.5194/amt-12-2979-2019.

Gal-Chen, T., and R. C. Somerville, 1975: On the use of a coordinate transformation for the solution of the Navier-Stokes equations. J. Comput. Phys., 17, 209-228, https://doi.org/ 10.1016/0021-9991(75)90037-6.

Grabowski, W. W., 2015: Untangling microphysical impacts on deep convection applying a novel modeling methodology. J. Atmos. Sci., 72, 2446-2464, https://doi.org/10.1175/JAS-D-14-0307.1.

— , and H. Morrison, 2017: Modeling condensation in deep convection. J. Atmos. Sci., 74, 2247-2267, https://doi.org/10.1175/ JAS-D-16-0255.1.

Grant, L. D., and S. C. van den Heever, 2015: Cold pool and precipitation responses to aerosol loading: Modulation by dry layers. J. Atmos. Sci., 72, 1398-1408, https://doi.org/10.1175/ JAS-D-14-0260.1.

Grosvenor, D. P., P. R. Field, A. A. Hill, and B. J. Shipway, 2017: The relative importance of macrophysical and cloud albedo changes for aerosol-induced radiative effects in closed-cell stratocumulus: Insight from the modelling of a case study. Atmos. Chem. Phys., 17, 5155-5183, https://doi.org/10.5194/ acp-17-5155-2017.

Halliwell, C., 2015: Subgrid turbulence scheme. Met Office Unified Model Documentation Paper 028, 14 pp.

Harrington, J. Y., 1997: The effects of radiative and microphysical processes on simulated warm and transition season Arctic stratus. Ph.D. dissertation, Dept. of Atmospheric Science, Colorado State University, 289 pp.

Heikenfeld, M., P. J. Marinescu, M. Christensen, D. Watson-Parris, F. Senf, S. C. van den Heever, and P. Stier, 2019: Tobac 1.2: Towards a flexible framework for tracking and analysis of clouds in diverse datasets. Geosci. Model Dev., 12, 4551-4570, https://doi.org/10.5194/gmd-12-4551-2019.

Heise, E., B. Ritter, and E. Schrodin, 2006: Operational implementation of the multilayer soil model TERRA. Deutscher Wetterdienst Tech. Rep., 22 pp.

Heymsfield, A. J., A. Bansemer, and C. H. Twohy, 2007: Refinements to ice particle mass dimensional and terminal velocity relationships for ice clouds. Part I: Temperature dependence. J. Atmos. Sci., 64, 1047-1067, https://doi.org/10.1175/JAS3890.1.

Hill, A. A., B. J. Shipway, and I. A. Boutle, 2015: How sensitive are aerosol-precipitation interactions to the warm rain representation? J. Adv. Model. Earth Syst., 7, 987-1004, https://doi.org/ 10.1002/2014MS000422.

Hong, S. Y., Y. Noh, and J. Dudhia, 2006: A new vertical diffusion package with an explicit treatment of entrainment processes. Mon. Wea. Rev., 134, 2318-2341, https://doi.org/10.1175/ MWR3199.1.

Iacono, M. J., J. S. Delamere, E. J. Mlawer, M. W. Shephard, S. A. Clough, and W. D. Collins, 2008: Radiative forcing by longlived greenhouse gases: Calculations with the AER radiative transfer models. J. Geophys. Res., 113, D13103, https://doi.org/ 10.1029/2008JD009944.

Iguchi, T., S. A. Rutledge, W.-K. Tao, T. Matsui, B. Dolan, S. E. Lang, and J. Barnum, 2020: Impacts of aerosol and environmental conditions on maritime and continental deep convective systems using a bin microphysical model. J. Geophys. Res. Atmos., 125, e2019JD030952, https://doi.org/10.1029/2019JD030952.

Jensen, M. P., 2019: Tracking Aerosol Convection Interactions Experiment (TRACER) science plan. Brookhaven National Laboratory Tech. Rep. BNL-212068-2019-INRE, 41 pp.

Khain, A. P., and B. Lynn, 2009: Simulation of a supercell storm in clean and dirty atmosphere using Weather Research and Forecast Model with spectral bin microphysics. J. Geophys. Res., 114, D19209, https://doi.org/10.1029/2009JD011827.

- A. Pokrovsky, M. Pinsky, A. Seifert, and V. Phillips, 2004: Simulation of effects of atmospheric aerosols on deep turbulent convective clouds using a spectral microphysics mixedphase cumulus cloud model. Part I: Model description and possible applications. J. Atmos. Sci., 61, 2963-2982, https:// doi.org/10.1175/JAS-3350.1.

- D. Rosenfeld, and A. Pokrovsky, 2005: Aerosol impact on the dynamics and microphysics of deep convective clouds. Quart. J. Roy. Meteor. Soc., 131, 2639-2663, https://doi.org/10.1256/ qj.04.62.

_ N. BenMoshe, and A. Pokrovsky, 2008: Factors determining the impact of aerosols on surface precipitation from clouds: 
An attempt at classification. J. Atmos. Sci., 65, 1721-1748, https://doi.org/10.1175/2007JAS2515.1.

— , L. R. Leung, B. Lynn, and S. Ghan, 2009: Effects of aerosols on the dynamics and microphysics of squall lines simulated by spectral bin and bulk parameterization schemes. J. Geophys. Res., 114, D22203, https://doi.org/10.1029/2009JD011902.

_ , and Coauthors, 2015: Representation of microphysical processes in cloud-resolving models: Spectral (bin) microphysics versus bulk parameterization. Rev. Geophys., 53, 247-322, https://doi.org/10.1002/2014RG000468.

Klemp, J. B., 1987: Dynamics of tornadic thunderstorms. Annu. Rev. Fluid Mech., 19, 369-402, https://doi.org/10.1146/ annurev.fluid.19.1.369.

Köhler, H., 1936: The nucleus in and the growth of hygroscopic droplets. Trans. Faraday Soc., 32, 1152-1161, https://doi.org/ 10.1039/TF9363201152.

Korolev, A., and Coauthors, 2020: A new look at the environmental conditions favorable to secondary ice production. Atmos. Chem. Phys., 20, 1391-1429, https://doi.org/10.5194/ acp-20-1391-2020.

Lac, C., and Coauthors, 2018: Overview of the Meso-NH model version 5.4 and its applications. Geosci. Model Dev., 11, 19291969, https://doi.org/10.5194/gmd-11-1929-2018.

Langhans, W., J. Schmidli, and B. Szintai, 2012: A SmagorinskyLilly turbulence closure for COSMO-LES: Implementation and comparison to ARPS. COSMO Newsletter, No. 12, Consortium for Small-Scale Modeling, Offenbach, Germany, 20-31.

Lebo, Z. J., 2014: The sensitivity of a numerically simulated idealized squall line to the vertical distribution of aerosols. J. Atmos. Sci., 71, 4581-4596, https://doi.org/10.1175/JASD-14-0068.1.

_ 2018: A numerical investigation of the potential effects of aerosol-induced warming and updraft width and slope on updraft intensity in deep convective clouds. J. Atmos. Sci., 75, 535-554, https://doi.org/10.1175/JAS-D-16-0368.1.

— invigoration due to increased aerosol concentration. Atmos. Chem. Phys., 11, 5407-5429, https://doi.org/10.5194/acp-115407-2011.

- H. Morrison, and J. H. Seinfeld, 2012: Are simulated aerosolinduced effects on deep convective clouds strongly dependent on saturation adjustment? Atmos. Chem. Phys., 12, 9941-9964, https://doi.org/10.5194/acp-12-9941-2012.

Lee, S. S., L. J. Donner, V. T. J. Phillips, and Y. Ming, 2008: The dependence of aerosol effects on clouds and precipitation on cloud-system organization, shear and stability. J. Geophys. Res., 113, D16202, https://doi.org/10.1029/2007JD009224.

Lin, J. C., T. Matsui, R. A. Pielke Sr., and C. Kummerow, 2006: Effects of biomass burning-derived aerosols on precipitation and clouds in the Amazon basin: A satellite-based empirical study. J. Geophys. Res., 111, D19204, https://doi.org/10.1029/ 2005JD006884.

Lock, A., J. Edwards, and I. Boutle, 2015: The parameterisation of boundary layer processes. Met Office Unified Model Documentation Paper 024, 71 pp.

Marinescu, P. J., S. C. van den Heever, S. M. Saleeby, S. M. Kreidenweis, and P. J. DeMott, 2017: The microphysical roles of lower-tropospheric versus midtropospheric aerosol particles in mature-stage MCS precipitation. J. Atmos. Sci., 74, 3657-3678, https://doi.org/10.1175/JAS-D-16-0361.1.

Masson, V., and Coauthors, 2013: The SURFEXv7.2 land and ocean surface platform for coupled or offline simulation of
Earth surface variables and fluxes. Geosci. Model Dev., 6, 929960, https://doi.org/10.5194/gmd-6-929-2013.

Matsui, T., S. Q. Zhang, S. E. Lang, W. K. Tao, C. Ichoku, and C. D. Peters-Lidard, 2020a: Impact of radiation frequency, precipitation radiative forcing, and radiation column aggregation on convection-permitting West African monsoon simulations. Climate Dyn., 55, 193-213, https://doi.org/10.1007/s00382-0184187-2.

- B. Bolan, T. Iguchi, S. A. Rutledge, W. Tao, and S. Lang, 2020b: Polarimetric radar characteristics of simulated and observed intense convective cores for a midlatitude continental and tropical maritime environment. J. Hydrometeor., 21, 501-517, https://doi.org/10.1175/JHM-D-19-0185.1.

Meyers, M. P., P. J. DeMott, and W. R. Cotton, 1992: New primary ice-nucleation parameterizations in an explicit cloud model. J. Appl. Meteor., 31, 708-721, https://doi.org/10.1175/15200450(1992)031<0708:NPINPI >2.0.CO;2.

_, R. L. Walko, J. Y. Harrington, and W. R. Cotton, 1997: New RAMS cloud microphysics parameterization. Part II: The two-moment scheme. Atmos. Res., 45, 3-39, https://doi.org/ 10.1016/S0169-8095(97)00018-5.

Miltenberger, A. K., P. R. Field, A. A. Hill, P. Rosenberg, B. J. Shipway, J. M. Wilkinson, R. Scovell, and A. M. Blyth, 2018: Aerosol-cloud interactions in mixed-phase convective clouds-Part 1: Aerosol perturbations. Atmos. Chem. Phys., 18, 3119-3145, https://doi.org/10.5194/acp-18-3119-2018.

Morrison, H., and W. W. Grabowski, 2008: Modeling supersaturation and subgrid-scale mixing with two-moment bulk warm microphysics. J. Atmos. Sci., 65, 792-812, https://doi.org/10.1175/ 2007JAS2374.1.

— , and J. A. Milbrandt, 2015: Parameterization of cloud microphysics based on the prediction of bulk ice particle properties. Part I: Scheme description and idealized tests. J. Atmos. Sci., 72, 287-311, https://doi.org/10.1175/JAS-D-14-0065.1.

_ J. A. Curry, and V. I. Khvorostyanov, 2005: A new doublemoment microphysics parameterization for application in cloud and climate models. Part I: Description. J. Atmos. Sci., 62, 1665-1677, https://doi.org/10.1175/JAS3446.1.

—, G. Thompson, and V. Tatarskii, 2009: Impact of cloud microphysics on the development of trailing stratiform precipitation in a simulated squall line: Comparison of one- and two-moment schemes. Mon. Wea. Rev., 137, 991-1007, https:// doi.org/10.1175/2008MWR2556.1.

- , and Coauthors, 2020: Confronting the challenge of modeling cloud and precipitation microphysics. J. Adv. Model. Earth Syst., 12, e2019MS001689, https://doi.org/10.1029/2019MS001689.

Nakanishi, M., and H. Niino, 2009: Development of an improved turbulence closure model for the atmospheric boundary layer. J. Meteor. Soc. Japan, 87, 895-912, https://doi.org/10.2151/ jmsj.87.895.

NASA LARC, 2014: DISCOVER-AQ P-3B Aircraft in-situ trace gas measurements. NASA LARC, accessed 9 August 2017, https:// doi.org/10.5067/AIRCRAFT/DISCOVER-AQ/AEROSOLTRACEGAS.

NCEP, 2000: NCEP FNL Operational Model Global Tropospheric Analyses, continuing from July 1999 (updated daily). NCAR Computational and Information Systems Laboratory Research Data Archive, accessed 31 December 2015, https://doi.org/ 10.5065/D6M043C6.

Peters-Lidard, C. D., and Coauthors, 2015: Integrated modeling of aerosol, cloud, precipitation and land processes at satelliteresolved scales. Environ. Modell. Software, 67, 149-159, https:// doi.org/10.1016/j.envsoft.2015.01.007. 
Petters, M. D., and S. M. Kreidenweis, 2007: A single parameter representation of hygroscopic growth and cloud condensation nucleus activity. Atmos. Chem. Phys., 7, 1961-1971, https:// doi.org/10.5194/acp-7-1961-2007.

Phillips, V. T. J., P. J. DeMott, and C. Andronache, 2008: An empirical parameterization of heterogeneous ice nucleation for multiple chemical species of aerosol. J. Atmos. Sci., 65, 2757-2783, https://doi.org/10.1175/2007JAS2546.1.

Rasmussen, R. M., I. Geresdi, G. Thompson, K. Manning, and E. Karplus, 2002: Freezing drizzle formation in stably stratified layer clouds: The role of radiative cooling of cloud droplets, cloud condensation nuclei, and ice initiation. J. Atmos. Sci., 59, 837-860, https://doi.org/10.1175/1520-0469(2002)059<0837: FDFISS $>2.0 . \mathrm{CO} ; 2$.

Reutter, P., and Coauthors, 2009: Aerosol- and updraft-limited regimes of cloud droplet formation: Influence of particle number, size and hygroscopicity on the activation of cloud condensation nuclei (CCN). Atmos. Chem. Phys., 9, 70677080, https://doi.org/10.5194/acp-9-7067-2009.

Ritter, B., and J.-F. Geleyn, 1992: A comprehensive radiation scheme for numerical weather prediction models with potential applications in climate simulations. Mon. Wea. Rev., 120, 303-325, https:// doi.org/10.1175/1520-0493(1992)120<0303:ACRSFN>2.0.CO;2.

Rosenfeld, D., U. Lohmann, G. B. Raga, C. D. O'Dowd, M. Kulmala, S. Fuzzi, A. Reissell, and M. O. Andreae, 2008: Flood or drought: How do aerosols affect precipitation? Science, 321, 1309-1313, https://doi.org/10.1126/science.1160606.

- E. Williams, M. O. Andreae, E. Freud, U. Pöschl, and N. O. Rennó, 2012: The scientific basis for a satellite mission to retrieve $\mathrm{CCN}$ concentrations and their impacts on convective clouds. Atmos. Meas. Tech., 5, 2039-2055, https://doi.org/ 10.5194/amt-5-2039-2012.

— precipitation-climate interactions. Rev. Geophys., 52, 750-808, https://doi.org/10.1002/2013RG000441.

Saleeby, S. M., and W. R. Cotton, 2004: A large-droplet mode and prognostic number concentration of cloud droplets in the Colorado State University Regional Atmospheric Modeling System (RAMS). Part I: Module descriptions and supercell test simulations. J. Appl. Meteor., 43, 182-195, https://doi.org/ 10.1175/1520-0450(2004)043<0182:ALMAPN >2.0.CO;2.

, and S. C. van den Heever, 2013: Developments in the CSURAMS aerosol model: Emissions, nucleation, regeneration, deposition, and radiation. J. Appl. Meteor. Climatol., 52, 26012622, https://doi.org/10.1175/JAMC-D-12-0312.1.

Sawamura, P., and Coauthors, 2017: HSRL-2 aerosol optical measurements and microphysical retrievals vs. airborne in situ measurements during DISCOVER-AQ 2013: An intercomparison study. Atmos. Chem. Phys., 17, 7229-7243, https:// doi.org/10.5194/acp-17-7229-2017.

Schättler, U., G. Doms, and C. Schraff, 2019: A description of the nonhydrostatic regional COSMO-model-Part VII: User's guide. COSMO Doc., 181 pp., http://www.cosmo-model.org/.

Seifert, A., and K. D. Beheng, 2006a: A two-moment cloud microphysics parameterization for mixed-phase clouds. Part 1: Model description. Meteor. Atmos. Phys., 92, 45-66, https:// doi.org/10.1007/s00703-005-0112-4.

_, and _ 2006b: A two-moment cloud microphysics parameterization for mixed-phase clouds. Part 2: Maritime vs. continental deep convective storms. Meteor. Atmos. Phys., 92, 67-82, https://doi.org/10.1007/s00703-005-0113-3.

— A. Khain, A. Pokrovsky, and K. D. Beheng, 2006: A comparison of spectral bin and two-moment bulk mixed-phase cloud microphysics. Atmos. Res., 80, 46-66, https://doi.org/ 10.1016/j.atmosres.2005.06.009.

— C. Köhler, and K. D. Beheng, 2012: Aerosol-cloud-precipitation effects over Germany as simulated by a convective-scale numerical weather prediction model. Atmos. Chem. Phys., 12, 709-725, https://doi.org/10.5194/acp-12-709-2012.

Seiki, T., and T. Nakajima, 2014: Aerosol effects of the condensation process on a convective cloud simulation. J. Atmos. Sci., 71, 833-853, https://doi.org/10.1175/JAS-D-12-0195.1.

Sheffield, A. M., S. M. Saleeby, and S. C. van den Heever, 2015: Aerosol-induced mechanisms for cumulus congestus growth. J. Geophys. Res. Atmos., 120, 8941-8952, https://doi.org/ 10.1002/2015JD023743.

Shipway, B. J., 2015: Revisiting Twomey's approximation for peak supersaturation. Atmos. Chem. Phys., 15, 3803-3814, https:// doi.org/10.5194/acp-15-3803-2015.

—, and A. A. Hill, 2012: Diagnosis of systematic differences between multiple parametrizations of warm rain microphysics using a kinematic framework. Quart. J. Roy. Meteor. Soc., 138, 2196-2211, https://doi.org/10.1002/qj.1913.

Shpund, J., and Coauthors, 2019: Simulating a mesoscale convective system using WRF with a new spectral bin microphysics: 1: Hail vs graupel. J. Geophys. Res. Atmos., 124, 14 072-14 101, https://doi.org/10.1029/2019JD030576.

Skamarock, W. C., and Coauthors, 2008: A description of the Advanced Research WRF version 3. NCAR Tech. Note NCAR/TN475+STR, 113 pp., https://doi.org/10.5065/D68S4MVH.

Smagorinsky, J., 1963: General circulation experiments with the primitive equations: I. The basic experiment. Mon. Wea. Rev., 91, 99-164, https://doi.org/10.1175/1520-0493(1963)091<0099: GCEWTP $>2.3 . \mathrm{CO} ; 2$.

Storer, R. L., and S. C. van den Heever, 2013: Microphysical processes evident in aerosol forcing of tropical deep convective clouds. J. Atmos. Sci., 70, 430-446, https://doi.org/10.1175/JAS-D-12-076.1.

,-- , and G. L. Stephens, 2010: Modeling aerosol impacts on convective storms in different environments. J. Atmos. Sci., 67, 3904-3915, https://doi.org/10.1175/2010JAS3363.1.

Stratton, R., M. Willet, S. Derbyshire, R. Wong, and M. Whitall, 2015: Convection schemes. Met Office Unified Model Documentation Paper 027, $174 \mathrm{pp}$.

Tao, W.-K., and X. Li, 2016: The relationship between latent heating, vertical velocity, and precipitation processes: The impact of aerosols on precipitation in organized deep convective systems. J. Geophys. Res. Atmos., 121, 6299-6320, https://doi.org/10.1002/2015JD024267.

, - _ A. Khain, T. Matsui, S. Lang, and J. Simpson, 2007: Role of atmospheric aerosol concentration on deep convective precipitation: Cloud-resolving model simulations. J. Geophys. Res., 112, D24S18, https://doi.org/10.1029/2007JD008728.

Twomey, S., 1977: The influence of pollution on the shortwave albedo of clouds. J. Atmos. Sci., 34, 1149-1152, https://doi.org/ 10.1175/1520-0469(1977)034<1149:TIOPOT>2.0.CO;2.

_ , and P. Squires, 1959: The influence of cloud nucleus population on the microstructure and stability of convective clouds. Tellus, 11, 408-411, https://doi.org/10.3402/tellusa.v11i4.9331.

van den Heever, S. C., G. G. Carrió, W. R. Cotton, P. J. DeMott, and A. J. Prenni, 2006: Impacts of nucleating aerosol on Florida storms. Part I: Mesoscale simulations. J. Atmos. Sci., 63, 1752-1775, https://doi.org/10.1175/JAS3713.1.

— G. L. Stephens, and N. B. Wood, 2011: Aerosol indirect effects on tropical convection characteristics under conditions of radiative-convective equilibrium. J. Atmos. Sci., 68, 699-718, https://doi.org/10.1175/2010JAS3603.1. 
and Coauthors, 2018: Aerosol-Cloud-Precipitation-Climate (ACPC) initiative: Deep Convective Cloud Group roadmap. ACPC Rep., 13 pp., http://acpcinitiative.org/Docs/ACPC DCC_Roadmap_171019.pdf.

Vié, B., J. P. Pinty, S. Berthet, and M. Leriche, 2016: LIMA (v1.0): A quasi two-moment microphysical scheme driven by a multimodal population of cloud condensation and ice freezing nuclei. Geosci. Model Dev., 9, 567-586, https://doi.org/10.5194/ gmd-9-567-2016.

Vogel, B., H. Vogel, D. B̈aumerr, M. Bangert, K. Lundgren, R. Rinke, and T. Stanelle, 2009: The comprehensive model system COSMO-ART-Radiative impact of aerosol on the state of the atmosphere on the regional scale. Atmos. Chem. Phys., 9, 8661-8680, https://doi.org/10.5194/acp-98661-2009.

Walko, R. L., and Coauthors, 2000: Coupled atmospherebiophysics-hydrology models for environmental modeling. J. Appl. Meteor., 39, 931-944, https://doi.org/10.1175/ 1520-0450(2000)039<0931:CABHMF>2.0.CO;2.
Walters, D., and Coauthors, 2017: The Met Office Unified Model global atmosphere 6.0/6.1 and JULES global land 6.0/6.1 configurations. Geosci. Model Dev., 10, 1487-1520, https:// doi.org/10.5194/gmd-10-1487-2017.

Wang, C., 2005: A modeling study of the response of tropical deep convection to the increase of cloud condensation nuclei concentration: 1. Dynamics and microphysics. J. Geophys. Res., 110, D21211, https://doi.org/10.1029/2004JD005720.

White, B., E. Gryspeerdt, P. Stier, H. Morrison, G. Thompson, and Z. Kipling, 2017: Uncertainty from the choice of microphysics scheme in convection-permitting models significantly exceeds aerosol effects. Atmos. Chem. Phys., 17, 12 145-12175, https:// doi.org/10.5194/acp-17-12145-2017.

Yuter, S. E., and R. A. Houze Jr., 1995: Three-dimensional kinematic and microphysical evolution of Florida cumulonimbus. Part II: Frequency distributions of vertical velocity, reflectivity, and differential reflectivity. Mon. Wea. Rev., 123, 1941-1963, https://doi.org/10.1175/1520-0493(1995)123<1941: TDKAME $>2.0 . \mathrm{CO} ; 2$. 